\title{
Exploring synergies between climate and air quality policies using long-term global and regional emission scenarios
}

\author{
Olivia Braspenning Radu ${ }^{a}$, Maarten van den Berg ${ }^{\text {a, }}$, Zbigniew Klimont ${ }^{\mathrm{c}}$, \\ Sebastiaan Deetman ${ }^{d}$, Greet Janssens-Maenhout ${ }^{e}$, Marilena Muntean ${ }^{\mathrm{e}}$, Chris Heyes ${ }^{\mathrm{c}}$, \\ Frank Dentener ${ }^{\mathrm{e}}$, Detlef P. van Vuuren ${ }^{\mathrm{a}, \mathrm{b}}$ \\ ${ }^{\text {a }}$ PBL - Netherlands Environmental Assessment Agency, Bilthoven, The Netherlands \\ b Utrecht University, Copernicus Institute for Sustainable Development, Department of Geosciences, Utrecht, The Netherlands \\ c International Institute for Applied Systems Analysis, Laxenburg, Austria \\ ${ }^{\mathrm{d}}$ Institute of Environmental Sciences, Leiden University, The Netherlands \\ e European Commission, Joint Research Centre, Institute for Environment and Sustainability, Ispra, Italy
}

\section{H I G H L I G H T S}

- The co-benefits of future climate and air pollution policies are assessed.

- A wide range of emission trajectories explores policy co-benefits.

- Climate mitigation policies are found highly relevant for air pollution control.

- Strengthened air pollution policies can offset growth in future air pollutants.

- Carbon-intensive Asian regions benefit from joint air pollutant and climate policy.

\section{A R T I C L E I N F O}

\section{Article history:}

Received 16 July 2015

Received in revised form

8 May 2016

Accepted 10 May 2016

Available online 13 May 2016

\section{Keywords:}

Climate policy

Air pollution policy

Scenarios

Co-benefits

Representative concentration pathways

\begin{abstract}
A B S T R A C T
In this paper, we present ten scenarios developed using the IMAGE2.4 framework (Integrated Model to Assess the Global Environment) to explore how different assumptions on future climate and air pollution policies influence emissions of greenhouse gases and air pollutants. These scenarios describe emission developments in 26 world regions for the 21 st century, using a matrix of climate and air pollution policies. For climate policy, the study uses a baseline resulting in forcing levels slightly above RCP6.0 and an ambitious climate policy scenario similar to RCP2.6. For air pollution, the study explores increasingly tight emission standards, ranging from no improvement, current legislation and three variants assuming further improvements. For all pollutants, the results show that more stringent control policies are needed after 2030 to prevent a rise in emissions due to increased activities and further reduce emissions. The results also show that climate mitigation policies have the highest impact on $\mathrm{SO}_{2}$ and $\mathrm{NO}_{\mathrm{x}}$ emissions, while their impact on $\mathrm{BC}$ and $\mathrm{OC}$ emissions is relatively low, determined by the overlap between greenhouse gas and air pollutant emission sources. Climate policy can have important co-benefits; a $10 \%$ decrease in global $\mathrm{CO}_{2}$ emissions by 2100 leads to a decrease of $\mathrm{SO}_{2}$ and $\mathrm{NO}_{\mathrm{X}}$ emissions by about $10 \%$ and $5 \%$, respectively compared to 2005 levels. In most regions, low levels of air pollutant emissions can also be achieved by solely implementing stringent air pollution policies. The largest differences across the scenarios are found in Asia and other developing regions, where a combination of climate and air pollution policy is needed to bring air pollution levels below those of today.
\end{abstract}

() 2016 Published by Elsevier Ltd.

\footnotetext{
* Corresponding author.

E-mail address: maarten.vandenberg@pbl.nl (M. van den Berg).
}

\section{Introduction}

Previous studies have shown important relationships between air pollution and climate change (Rogelj et al., 2014b; Bollen and Brink, 2012; McCollum et al., 2012; van Vuuren et al., 2006; UNEP 
and WMO, 2011). First of all, air pollutants often originate from the same economic activities as greenhouse gases (GHGs), e.g. combustion of fossil fuels. This means that greenhouse gas abatement activities may lead to important co-benefits for air quality. Secondly, many air pollutants also change the radiative forcing, leading to either a warming effect, e.g. by black carbon and methane, or a cooling effect, e.g. by sulfur dioxide emissions and subsequent formation of sulphate aerosols. Thirdly, climate change can lead to changes in concentrations of air pollutants driven by changes in emissions, formation and removal mechanisms influenced by meteorology (Jacob and Winner, 2009). And finally, air pollution can influence the functioning of natural systems and agriculture, with an impact on among others crop growth and the carbon and nitrogen cycles. These linkages can lead to both co-benefits and trade-offs in reduction strategies. For instance, climate policies often also reduce regional and urban air pollution (McCollum et al., 2012; Bollen and Brink, 2012; Smith and Wigley, 2006; Rao et al., 2006; van Vuuren et al., 2006; Syri et al., 2001) or lead to lower costs in achieving air pollution targets (van Vuuren et al., 2006). Such co-benefits could represent an important incentive to increase the interest of developing countries in contributing to a global climate policy.

Air pollution scenarios have traditionally been developed from a regional perspective; several projections have been made for Europe, Asia, and North America (e.g. Wang et al., 2014; Klimont et al., 2009; Amann et al., 2005). While the air pollution projections developed with regional models include a lot of details about anthropogenic sources and short-term transitions, they typically do not cover land-use related sources in a consistent way. Recently, the interest in global air pollution scenarios has significantly increased, given the growing evidence that emissions in various world regions can influence the background concentrations in other regions (e.g. Chuwah et al., 2013; TF-HTAP, 2010). Moreover, there has been considerable interest in the relationship between emissions of air pollutants and greenhouse gases. In response, global scenarios with harmonized assumptions about anthropogenic $\mathrm{CO}_{2}$ emissions and key air pollutants' evolution have been developed with, for example, the GAINS (Greenhouse Gas and Air Pollution Interactions and Synergies) model (Cofala et al., 2007; Klimont et al., in preparation, 2016) and already used in assessments in either mid-term (UNEP and WMO, 2011; Shindell et al., 2012; Rafaj et al., 2013; Rao et al., 2013; McCollum et al., 2013) or long-term (Rogelj et al., 2014a, 2014b; Riahi et al., 2012).

The recently developed Representative Concentration Pathways (RCPs) represent a set of comprehensive scenarios for climate policy that also include corresponding global air pollutant emission trajectories (van Vuuren et al., 2011b; Moss et al., 2010). The RCPs have been used as input for the CMIP5 experiments run by a large number of climate and earth system models informing the IPCC's fifth assessment report (Taylor et al., 2012). The RCPs are therefore attractive to use in a joint analysis of global air pollution and climate change. Although the RCPs describe plausible pathways with respect to air pollution emissions, they do not cover the full range of possible policies and outcomes (van Vuuren et al., 2011a; Amann et al., 2013). The underlying reason is that all RCPs, having a focus on climate policy, assumed a progressive reduction of air pollutant emissions with increasing wealth. However, these assumptions were not necessarily consistent across RCPs. This implies that for air pollution policies, the RCP set neither includes a counterfactual "no further control" nor an aggressive best available technology scenario.

In this study, we describe a set of RCP-like scenarios which allow exploring a wide range of possible climate and air pollution control futures and their linkages. These scenarios include emissions of greenhouse gases, sulfur dioxide $\left(\mathrm{SO}_{2}\right)$, organic carbon $(\mathrm{OC})$, black carbon $(\mathrm{BC})$, nitrogen oxides $\left(\mathrm{NO}_{\mathrm{x}}\right)$, carbon monoxide $(\mathrm{CO})$, and non-methane volatile organic compounds (NMVOC) on short and long term time frames. The set of scenarios is fully developed within the IMAGE 2.4 integrated assessment model framework, which has also contributed to the development of the RCP scenarios (van Vuuren et al., 2011c). The scenario set makes full use of the detailed long-term modelling of the energy system in IMAGE and allows for an analysis of the effects of climate and air pollutant policy assumptions on air pollutant emissions. Previously, Rogelj et al. (2014a) have also created long term air pollutant scenarios consistent with the RCP $\mathrm{CO}_{2}$ emission pathways. They have estimated instead how on an aggregate level air pollutant emissions vary with different $\mathrm{CO}_{2}$ emission pathways and subsequently applied different levels of air pollution control to the RCP $\mathrm{CO}_{2}$ emission pathways (Rao et al., 2013).

The paper is structured as follows. Section 2 describes the methods used to develop the scenarios and the main assumptions behind the baseline scenario. The results for different air pollutants emission trends in different scenarios are presented in Section 3 and discussions on the main findings are given in Section 4, which are concluded in Section 5.

\section{Methods}

\subsection{IMAGE 2.4 model framework}

The IMAGE integrated assessment model framework allows a scenario analysis of global environmental change (Bouwman et al., 2006). Main scenario assumptions and model inputs include population evolution, economic growth, technology development, lifestyle parameters and trade assumptions. Based on these drivers, the model describes the development of both the energy and the agricultural system in considerable detail. The resulting greenhouse gas and air pollutant emissions and land-use change parameters are used to assess climate change and other environmental variables.

Emissions from the energy system and industrial processes are calculated by The Image Energy Regional model (TIMER). This expert energy model simulates greenhouse gas and air pollutant emissions up to 2100 for 12 different primary energy carriers (fossil and biomass) in 26 world regions, under a range of scenario assumptions. Energy system emissions in TIMER are calculated for 5 energy demand sectors and energy production and conversion. The TIMER model focuses on dynamic relationships within the energy system, such as inertia and learning-by-doing in capital stocks, depletion of the resource base and trade among different regions. A carbon tax can be used to induce a dynamic response, such as an increased use of low- or zero-carbon technologies, energy efficiency improvements and end-of-pipe emission reduction technologies.

Land-use and land-use change in the IMAGE model is governed by the demand for food, feed and energy crops. Demand increases for these products could lead to expansion of agricultural land, causing deforestation and associated greenhouse gas and air pollutant emissions. In addition, IMAGE covers emissions associated with agricultural activities such as rice production and animal husbandry. Some natural emissions sources are included as well, mostly as a constant emission source based on EDGAR data. In some cases, natural emission sources are coupled to dynamic variables such as temperature and forest extent, e.g. in the case of emissions associated with natural forest fires.

Our scenario analysis focuses on long-term projections of emissions from the energy system, which dominate total emissions for most species, and industrial processes. Although we also calculate emissions associated with land-use and land-use change, 
we have not included specific policy assumptions to reduce these emissions.

\subsection{Scenario assumptions}

\subsubsection{Scenario design}

The scenarios developed for this study are described by a framework consisting of two main axes, one describing the level of climate policy and the second describing the level of air pollution control, both ranging from no policy to stringent emission control (see Table 1). This results in a scenario matrix that defines a total of 10 different scenarios. Along the climate policy axis, we distinguish two types of scenarios similar to two of the RCPs. These are the OECD baseline scenario (BL), which leads to a forcing level similar to RCP6, and a scenario that follows a more ambitious trajectory (450) similar to the RCP2.6 (van Vuuren et al., 2011c). These are further discussed in section 2.2.2.

For the air pollution policies we use 2005 as the base year and make the following set of key policy assumptions, in increasing order of stringency (see Table 1):

1. No improvement of policies after 2005, resulting in frozen emission factors for all energy system emission factors (FRZ).

2. Implementation of current policies, of which the full effects are realized by 2030; thereafter no change in legislation and therefore in emission factors (CLE).

3. Further tightening of current legislation (CLE) after 2030; the level and pace of introducing additional policies is based on economic development in a given region - using Kuznets theory, resulting in further decreasing emission factors (CLE KZN).

4. Implementation of current best available technology by 2030 , maximum technically feasible reductions; no change thereafter (MFR).

5. MFR with further improvement after 2030 (MFR KZN), similar to CLE KZN.

The air pollution scenarios thus explore a wide range of possible assumptions. Some parts of this range may be viewed as sensitivity runs. For example, given historical reductions in emission factors, a frozen emission factor (after 2005) should be seen as indicative for the upper bound of possible trajectories. Limited improvement in emission factors may happen when institutional and political barriers lead to failure in implementation of planned legislation. The air pollution policies are discussed in more detail in section 2.2.3.

\subsubsection{Climate policy scenarios}

In this study, we include two basic climate and energy system policy scenarios: 1) a baseline scenario, similar to RCP6 and in the order of $6.7 \mathrm{~W} / \mathrm{m}^{2}$ in 2100 and 2) a stringent $450 \mathrm{ppm} \mathrm{CO}_{2}$-eq climate policy scenario (similar to RCP2.6). The latter scenario is likely to comply with the UNFCCC target to limit global temperature change to $2{ }^{\circ} \mathrm{C}$ by the end of this century, for which we assume full flexibility to mitigate greenhouse gas emissions across time, sources, and gases.

For the baseline scenario, we use the IMAGE implementation of the OECD Environmental Outlook baseline (OECD, 2012). This scenario describes the development of the energy system and land use in the absence of climate policy. It assumes a medium development for main driving forces such as income, population and energy use. By 2050 the population will increase to around 9 billion and subsequently more-or-less stabilize (UNDESA, 2011). Assuming no fundamental change in current policies, fossil fuels are expected to retain a large market share in most situations as their market price is expected to stay below that of alternative fuels. Feeding a growing population with a more protein-rich diet requires increases in agricultural production. The necessary expansion of agricultural land is partly offset by improved agricultural yields. Deforestation due to agricultural expansion is projected to peak in 2030. Together, this leads to high levels of greenhouse gas emissions, with a resulting radiative forcing of around $6.7 \mathrm{~W} / \mathrm{m}^{2}$ in 2100 .

The climate policy scenario is derived from the baseline scenario by implementing an equal carbon tax in all regions and sectors. The carbon tax induces changes in the energy system through a price mechanism, i.e. increased use of zero and low carbon technologies, energy efficiency and reduction of non- $\mathrm{CO}_{2}$ emissions, due to changes in activities. The baseline and climate policy scenarios are similar to the ones used by van Vliet et al. (2012). The main characteristics and the differences due to the additional air pollution policy scenario assumptions are discussed in section 3 .

\subsubsection{Air pollution policy scenarios}

Air pollution policies and the historic development of air pollution emissions are represented by time-dependent implied emission factors (EFs). Here, implied EFs are the product of emission factors and end-of-pipe measures. Air pollution emissions are calculated by multiplying activity levels and the corresponding EFs, following the so-called Tier 1 approach from IPCC (2006). Air pollution policies can be represented in this equation by changing these EFs over time.

$\operatorname{Emissions}_{S}(\mathrm{t})=\mathrm{EF}_{\mathrm{S}, \mathrm{a}, \mathrm{b}}(\mathrm{t}) \times \operatorname{Activity}_{\mathrm{S}, \mathrm{a}, \mathrm{b}}(\mathrm{t})$

In this equation, the Emissions are those of a specific substance ( $S$, a greenhouse gas or air pollutant); $E F$ is the activity specific implied emission factor per (a) energy carrier and (b) sector at time $t$; the Activity refers to the annual energy input (e.g. for the production of cement) in a given sector. The sectors identified in the energy system are: industry, transport, residential, service,

Table 1

Overview of the 10 scenarios developed within this study.

\begin{tabular}{|c|c|c|c|}
\hline \multirow[t]{2}{*}{ Scenario name } & \multicolumn{2}{|l|}{ Air pollution policy } & \multirow[t]{2}{*}{ Climate policy } \\
\hline & $2005-2030$ & $2030-2100$ & \\
\hline BL FRZ & 2005 frozen EF values & 2005 frozen EF values & No climate policy \\
\hline $450 \mathrm{FRZ}$ & 2005 frozen EF values & 2005 frozen EF values & $450 \mathrm{ppm}$ scenario \\
\hline BL CLE & EF decrease towards 2030 CLE & 2030 CLE EF values frozen & No climate policy \\
\hline BL CLE KZN & EF decrease towards 2030 CLE & Continual decrease of EF towards 2100 using GDP driven EF decline & No climate policy \\
\hline $450 \mathrm{CLE}$ & EF decrease towards 2030 CLE & 2030 CLE EF values frozen & 450 ppm scenario \\
\hline 450 CLE KZN & EF decrease towards 2030 CLE & Continual decrease of EF towards 2100 using GDP driven EF decline & 450 ppm scenario \\
\hline BL MFR & EF decrease towards 2030 MFR & 2030 MFR EF values frozen & No climate policy \\
\hline BL MFR KZN & EF decrease towards 2030 MFR & Continual decrease of EF towards 2100 using GDP driven EF decline & No climate policy \\
\hline 450 MFR & EF decrease towards 2030 MFR & 2030 MFR EF values frozen & 450 ppm scenario \\
\hline 450 MFR KZN & EF decrease towards 2030 MFR & Continual decrease of EF towards 2100 using GDP driven EF decline & 450 ppm scenario \\
\hline
\end{tabular}


electricity generation, transformation (mostly refineries), losses (in fuel production and transportation), and marine bunkers. For industrial processes, emissions for the following sectors are calculated: copper smelting, iron and steel, paper, chemicals and solvents, zinc, cement, adipic and nitric acid production, chemicals bulk production and feedstock production and use.

The emission factor development can be divided into three distinct periods: a historical period (up to 2005), the 2005-2030 period and the 2030-2100 period. The historical emission factors are calibrated to EDGAR v4.2 data (EC-JRC/PBL, 2011). For the 2005-2030 period the emission factors are based on the information available from the GAINS model ECLIPSE v4a scenarios (Amann et al., 2011; Klimont et al., in preparation, 2016) where the impact of current legislation and stringent mitigation is modeled in detail and further converted into TIMER model categories. After 2030 the emission factors are either frozen or are allowed to evolve as a function of income, similar to what is sometimes referred to as the Environmental Kuznets Curve (Stern, 2003; van Ruijven et al., 2008). The detailed implementation of this evolution of emission factors is discussed below.

2.2.3.1. Historical period (1970-2005). For the period 1970-2005, historical data on emission factors derived from the EDGAR v4.2 database has been used (EC-JRC/PBL, 2011). As the EDGAR v4.2 data is more detailed in terms of activities, implied emissions factors were calculated by technology weighting the more detailed EDGAR $\mathrm{v} 4.2$ emission factors to the aggregated level of the TIMER emission factors. In a few cases, i.e. for Heavy Liquid Fuel and Light Liquid Fuel, the uncommon use of some fuels was left out in the calculation of the implied emission factor (for the industry combustion, transportation, residential, services, power and other sectors in certain regions), in order to obtain more representative emission factors. Additional information can be found in Table ES1 of the Supplementary Material.

2.2.3.2. $2005-2030$ period. For the $2005-2030$ period, the GAINS model was used to develop several air pollution scenarios drawing on the information about implementation of current policies and about the technologically feasible mitigation opportunities beyond these policies in all key sectors and regions (Rao et al., 2013; Amann et al., 2013; Klimont et al., in preparation, 2016). The GAINS model structure and spatial resolution is much more detailed than TIMER and therefore aggregated (to TIMER resolution) emission factors were calculated and implemented in TIMER for 2030, assuming a linear interpolation starting from the historical emission factors in 2005 to 2030 (equation (2)). Three different sets of assumptions for EFs were used for 2030 (Rafaj et al., 2013): 1) frozen emission factors (FRZ), 2) current legislation (CLE), and 3) maximum feasible reduction (MFR), see section 2.2.1.

$E F(t)=E F_{2005}-\left(E_{2005}-E F_{2030}\right) /(2030-2005) \times(t-2005)$

Since for the 1970-2005 period EDGAR v4.2 data were used, the GAINS emission factors used for 2030 needed to be checked against the EDGAR data. In most cases, the data were found to be consistent and the GAINS data was used as described above. In a small number of cases, the GAINS emission factor values for 2030 were found to be higher than the EDGAR 2005 values. In this case, the emission factors were kept constant over the 2005-2030 period (at the level of the EDGAR data). In a few other cases, it was not possible to reconcile the GAINS, TIMER and EDGAR sectoral break-down. In those cases, it was assumed that emission factors would improve over time driven by income levels, similar to the improvement of emission factors in some scenarios after 2030. This arises for instance in the determination of emission factors for light and heavy liquid fuels, where the GAINS model has a higher resolution in which diesel and gasoline are distinguished separately both in activity data and in respective legislation.

2.2.3.3. 2030 - 2100 period. For the period after 2030, it is assumed that emission factors either remain constant at 2030 levels (the CLE and MFR scenarios) or further decline driven by regional income levels (the CLE KZN and MFR KZN scenarios). The development of emission factors depends on two main variables: 1 ) two income thresholds in terms of GDP per capita (see Table 2) and 2) two sets of fixed emission factor target values, corresponding to the income thresholds, for each pollutant. The income threshold is reached at a different point in time for each region, depending on the assumed economic development.

After the regional income level exceeds the first income threshold the emission factor starts to decrease from its 2030 value towards the first emission factor target value. This target value is equal to the average 2005 emission factor for the OECD regions. When a region reaches the second threshold, the emission factor will decline further towards the second target value. This second target value is defined as the minimum of the 2030 emission factor across the OECD regions. When a region crosses the first income threshold, the rate of emission factor decline is equal to the rate of decline in the 2005-2030 period relative to the previous year up to the moment the emission factor falls below the OECD 2030 minimum (equation (3)). For regions that have an emission factor equal to or lower than the OECD 2030 minimum and are at an income level above 'Threshold 2', the emission factor still continues to decline but at a lower rate (half of the 2005-2030 rate of decline).

$\mathrm{EF}(\mathrm{t})=\mathrm{EF}(\mathrm{t}-1) \times\left[1-\left(\mathrm{EF}_{2005}-\mathrm{EF}_{2030}\right) /(2030-2005)\right]$

In our implementation it is also assumed that developing countries will implement policies slightly earlier than developed countries in the past, due to a much faster and cheaper technology transfer. To this end, we assume that income thresholds are not static but declining linearly over time, so that developing countries implement abatement technologies at lower income levels (see Table 2). Also for $\mathrm{SO}_{2}$ slightly different income threshold values are used as analysis has shown that for this pollutant EFs start to decline somewhat earlier than for other pollutants (e.g. Rafaj et al., 2014). Examples of EFs development after 2030 for a number of species, sectors, and energy carriers can be found in the Supplementary Material.

\subsubsection{The IMAGE-PEGASOS scenario datasets}

The set of 10 scenarios (as summarized in Table 1), combining climate and air pollution policies, generate emission sets for $\mathrm{CO}_{2}$ and $\mathrm{CH}_{4}$ and several air pollutants. Scenario results have been downscaled in a final step from region to country level following the same method described by van Vuuren et al. (2007). The method employs the IPAT equation (Impact equals Population $\mathrm{x}$ Affluence $\mathrm{x}$ Technology). To calculate the downscaled emission levels it uses country level population projections and an assumption of slow convergence in country scale income levels and emission factors within regions. Country-level emissions values were subsequently downscaled to a $0.5 \times 0.5^{\circ}$ grid by changing all grid cells within a country proportionally (see also Fig. 4). These downscaled emission sets can be used as input to chemical transport models allowing the calculation of ambient concentrations.

\section{Scenario results}

The scenario results show a rather broad range of different development trajectories in terms of air pollutant emissions. Below 
Table 2

Thresholds (GDP per capita in 2005 US\$) used for EF scenario development.

\begin{tabular}{|c|c|c|}
\hline & Threshold 1 (EF starts declining towards average 2005 EF of OECD regions) & Threshold 2 (EF starts declining towards minimum 2030 OECD EF) \\
\hline \multicolumn{3}{|c|}{ For all gases except $\mathrm{SO}_{2}$} \\
\hline 2005 & 10.000 & 35.000 \\
\hline 2100 & 5.000 & 15.000 \\
\hline \multicolumn{3}{|c|}{ For $\mathrm{SO}_{2}$} \\
\hline 2005 & 8.000 & 30.000 \\
\hline 2100 & 2.000 & 10.000 \\
\hline
\end{tabular}
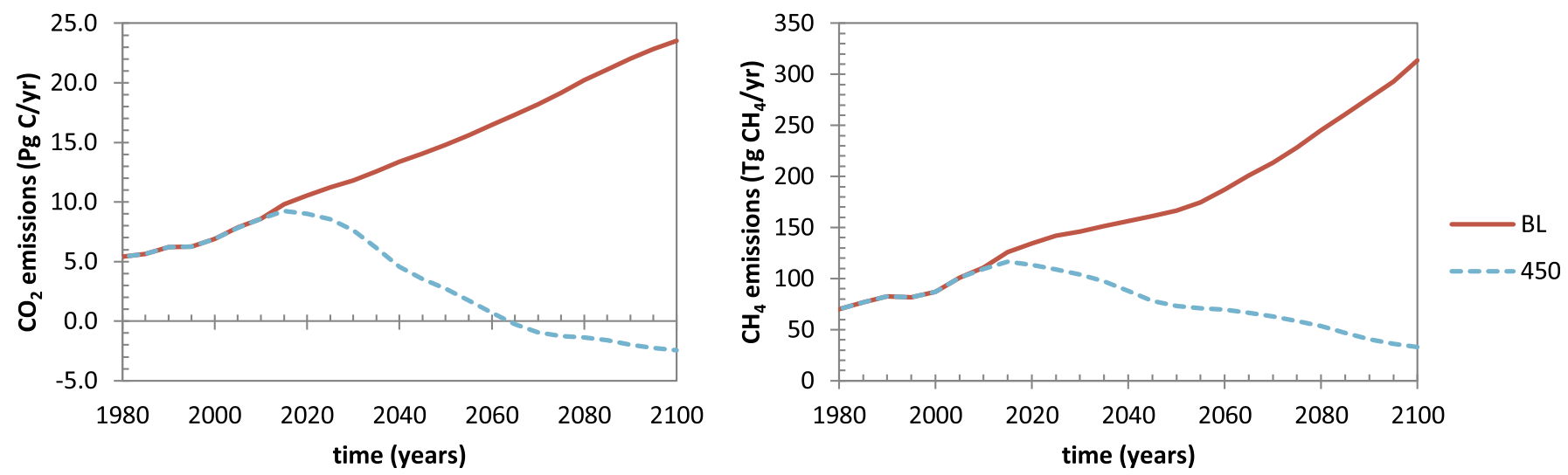

Fig. 1. $\mathrm{CO}_{2}$ and $\mathrm{CH}_{4}$ energy system emissions for the baseline (BL) and climate policy scenarios (450), independent of air pollution policy assumptions.

we discuss the results for individual pollutants.

\subsection{Greenhouse gas emissions $\left(\mathrm{CO}_{2}\right.$ and $\left.\mathrm{CH}_{4}\right)$}

In this study, $\mathrm{CO}_{2}$ and $\mathrm{CH}_{4}$ emissions are affected only by climate policy. This implies that air pollution policies do not have an impact on energy demand (e.g. through implementation of end-of-pipe measures). In the baseline scenario (without climate policy) total anthropogenic emissions of $\mathrm{CO}_{2}$ and $\mathrm{CH}_{4}$ increase almost $300 \%$ and $90 \%$ by 2100 respectively, compared to 2005 levels. Energy system $\mathrm{CO}_{2}$ and $\mathrm{CH}_{4}$ emissions increase by about $300 \%$ (see also van Vliet et al., 2012). In contrast, in the 450 ppm scenario, substantial reductions are needed: total greenhouse gas emissions peak before 2020 , are lower by around 50\% in 2050 compared to 2005, and are slightly above zero by 2100 . While total energy system $\mathrm{CH}_{4}$ emissions are reduced by about $50 \%$ (see Fig. 1 ), the $\mathrm{CO}_{2}$ emissions are in fact reduced more than total greenhouse gas emissions and become negative in the latter half of the century by using BECCS (bio-energy with carbon capture and storage). $\mathrm{CH}_{4}$ emission reductions in the energy sector are realized predominantly by fuel substitution while agricultural emissions are reduced by introducing measures affecting enteric fermentation and emissions from animal manure. In the model, a rapid transformation of the energy system to a lowcarbon system is achieved via a global carbon price, reaching a level of $325 \mathrm{USD} / \mathrm{tCO}_{2}$-eq in 2050 . The changes in the energy system include: implementation of energy efficiency, substitution of high with low carbon fuels and rapid introduction of zero-carbon technologies, including renewables, nuclear, and CCS (carbon capture and storage).

\section{2. $N O_{X}$ emissions}

Transportation and electricity generation are the most important sources of $\mathrm{NO}_{\mathrm{X}}$. Reduction of $\mathrm{NO}_{\mathrm{X}}$ emissions can be achieved by fuel switching, efficiency improvement, and implementation of measures involving catalytic reduction; the latter being most efficient for both mobile and stationary sources. Without further application of such measures, $\mathrm{NO}_{\mathrm{X}}$ emissions are expected to increase rapidly - as depicted by the 'frozen emission factors' baseline (BL FRZ) scenario.

The baseline scenarios (i.e. those without climate policy) show a wide range of possible $\mathrm{NO}_{\mathrm{X}}$ emission trajectories. The MFR scenario would result in 60\% global emissions reduction compared to 2005 levels in the next decades, which is consistent with the results also found by Cofala et al. (2007). However, emissions within the current legislation scenario (CLE) are expected to remain relatively stable up to 2030 (see Fig. 2). One important reason for this is that the further introduction of emission reduction technologies and measures (e.g. stricter emissions standards in the transport sector) is counterbalanced by the rapid growth of fuel consumption, especially for power generation. Eventually, this leads to a rebound of the emission trajectory indicating that further legislation, beyond implemented in the CLE scenario, would be needed to constrain the emissions. In contrast, in the Kuznets (CLE KZN) scenario emissions remain more-or-less constant before decreasing after 2050 at a global scale as a result of declining emissions factors that counteract the growth in activities. Only in the second half of the century emissions decline due to a slowdown in the growth of activities. Also, the relative share of the transport sector emissions decreases after 2050 significantly from almost 50\% of energy emissions to a value between $2 \%$ and $14 \%$, depending on the type of air pollution policy.

For scenarios with climate policy, a decline in NOx emissions is observed. For the 450 CLE scenario, emissions in 2030 are reduced by almost $40 \%$ compared to 2005 and they are lower by about $25 \%$ compared to the CLE scenario without climate policy. Also, $\mathrm{NO}_{\mathrm{x}}$ emissions peak earlier through systemic changes in the energy system. These systemic changes, such as fuel switches, a transition to alternative fuel vehicles and an increased use of renewable energy, induced by climate policy result in an overall decline of emissions. Thus, differences between the various air pollution scenarios become less pronounced. In general, in the power sector a $10 \%$ reduction in $\mathrm{CO}_{2}$ emissions leads to a $5 \%$ reduction in $\mathrm{NO}_{\mathrm{X}}$ emissions. The available data also suggests that this 'co-benefit' 

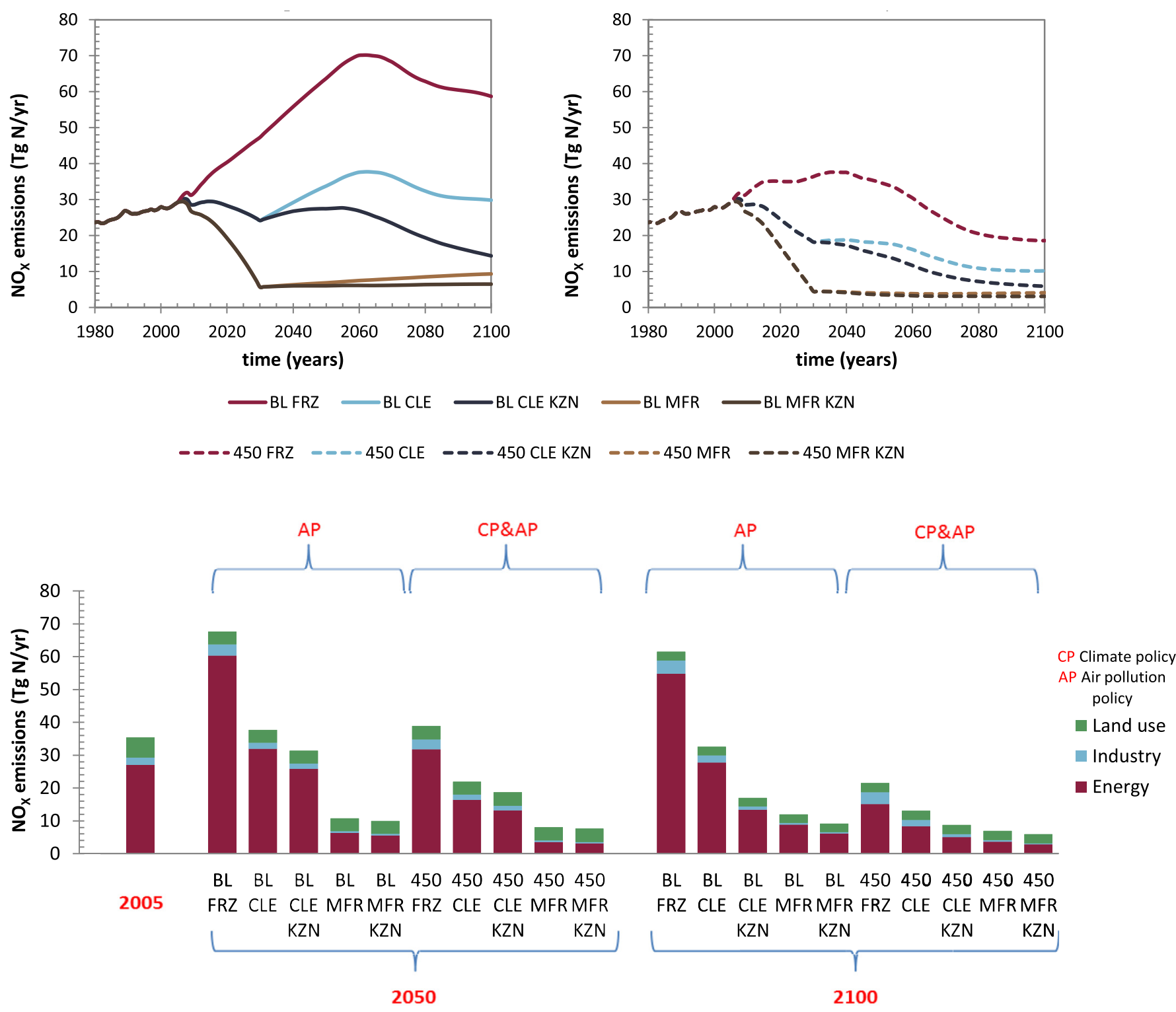

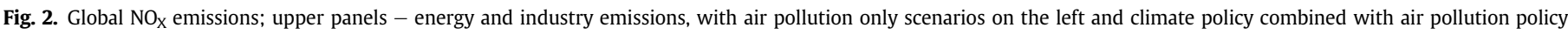

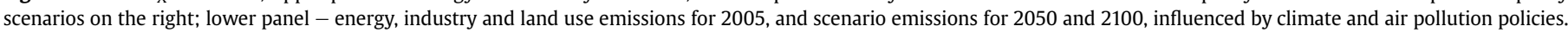

ratio is somewhat reduced on the long term, i.e. lower $\mathrm{NO}_{\mathrm{X}}$ reduction for a given reduction of $\mathrm{CO}_{2}$ (van Vuuren et al., 2011a).

The strongest reductions (in the long term) are achieved under a combined climate and air pollution scenario. The impact of climate policy under current air pollution policies is a reduction of $\mathrm{NO}_{\mathrm{X}}$ emissions to $10 \mathrm{Tg} \mathrm{N} / \mathrm{yr}$ - almost a third of the current level. Trends may differ regionally; developed regions show declining levels of $\mathrm{NO}_{\mathrm{X}}$ emissions in the absence of further policies, while at the same time many other regions exhibit large increases in emissions. For the latter, either very strict air pollution policies (MFR KZN) are required or a combination of climate and air pollution policies (450 CLE KZN) to reduce $\mathrm{NO}_{X}$ emissions below current levels in 2050 (see Fig. 4), whereas India and some African regions reach levels lower than in 2005 under very strict air pollution policies.

\section{3. $\mathrm{SO}_{2}$ emissions}

For most regions, the energy sector is a key source of $\mathrm{SO}_{2}$ emissions. However, industrial combustion and processes, refineries and in some regions transportation can have significant shares. All scenarios where some form of climate or air pollution policy is included show a rapid reduction in $\mathrm{SO}_{2}$ emissions until 2030 (see Fig. 3), although the CLE scenario shows an increase in emissions thereafter, as emissions factors do not decline further after 2030. Climate policy, on the other hand has a lasting and relatively strong impact on reducing $\mathrm{SO}_{2}$ emissions. Data from a set of scenarios from different models suggests that in the context of climate mitigation, on average a $10 \%$ reduction in $\mathrm{CO}_{2}$ emissions also leads to a $10 \%$ reduction in $\mathrm{SO}_{2}$ emissions (van Vuuren et al., 2008); this is confirmed by the scenarios in this study. The strongest reduction of $\mathrm{SO}_{2}$ emissions is achieved mainly in the power sector, in particular by the progressive phase-out of coal power plants. $\mathrm{SO}_{2}$ emissions are also reduced with the introduction of plants with CCS, as flue gas desulphurization is required in such plants.

The fall of $\mathrm{SO}_{2}$ emissions in the climate policy scenarios is stronger than in air quality policy scenarios where only end-of-pipe measures are implemented. The results also demonstrate that 

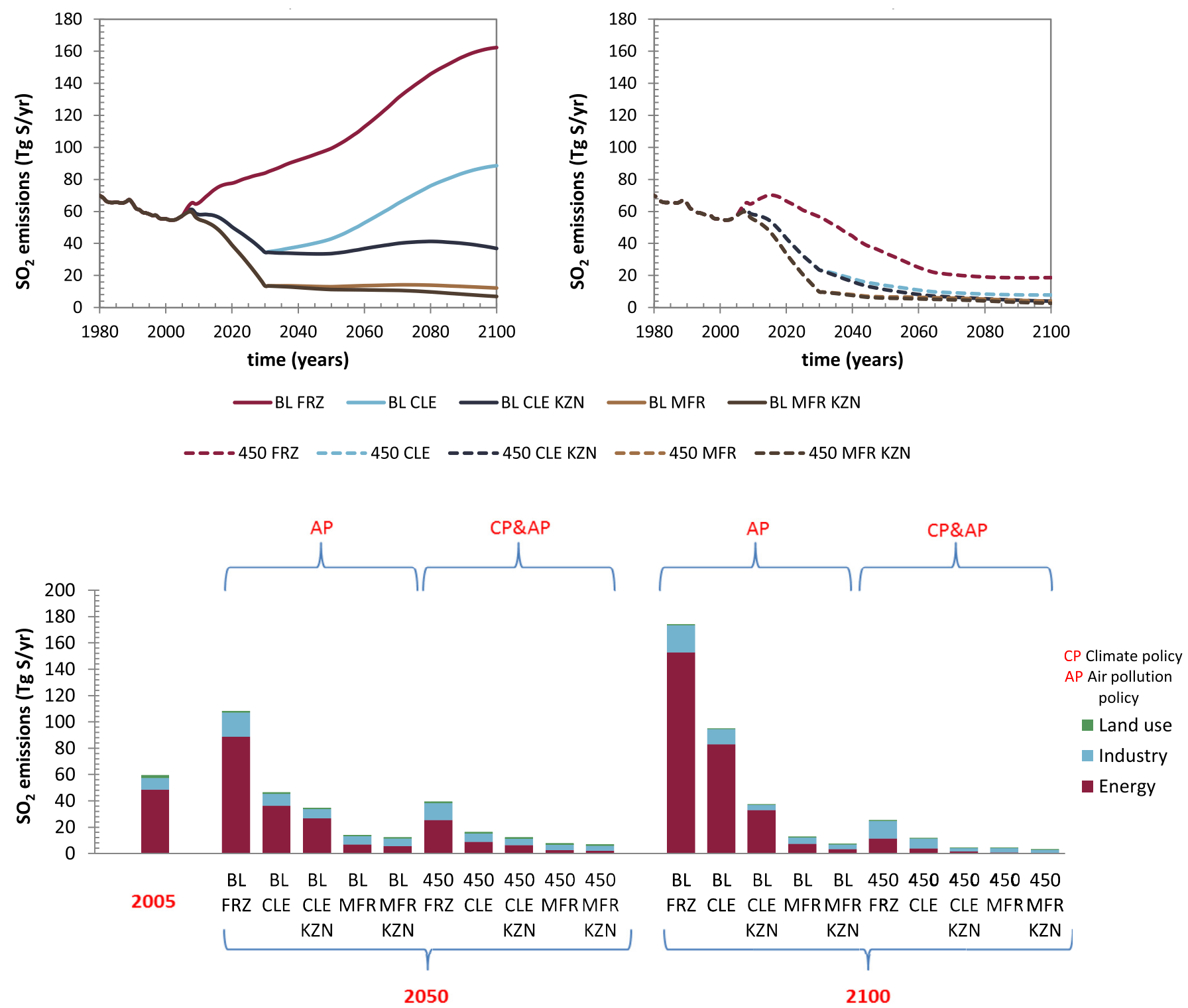

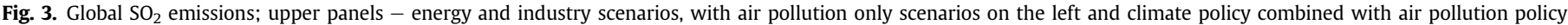

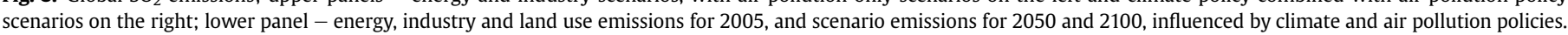

emission differences that result from the use of different emission factors, corresponding to a range of air pollution control policies, in the context of climate policy have a relatively small impact, specifically in the long term. At the end of the century, $\mathrm{SO}_{2}$ is reduced in several scenarios to nearly zero.

Regionally, the projected increase in $\mathrm{SO}_{2}$ emissions in the absence of additional policies (BL FRZ) - specifically in India and China - can be abated by a combination of air pollution and climate policies, while for some developed regions a decline from 2005 levels is projected even in the absence of additional policies. In India $\mathrm{SO}_{2}$ emissions increase even under air pollution policies (BL CLE KZN), whereas climate policies reduce emissions significantly (see Fig. 4).

\subsection{NMVOC emissions}

In industrialized countries, anthropogenic NMVOC emissions originate mainly from the transport and industry sectors, more specifically from solvent use. In developing countries with high use of solid fuels for cooking, the residential sector is an important contributor to NMVOC emissions followed by transport. The source structure might change quickly as transport emissions can be effectively controlled and growth in chemical industry and personal wealth will drive solvent use related emissions, see for example recent developments in China (Wei et al., 2008) and India (Sharma et al., 2015). Globally, the majority of NMVOC emissions, however, originates from natural sources, e.g., forests but also open biomass burning.

Global NMVOC emissions are expected to decline (except in the BL FRZ case) until 2030 by $25 \%$ to over $60 \%$ compared to 2005 , depending on the implemented policies. However, in absence of further air quality policies, emissions increase again until 2060 (Fig. 5). After 2060, higher oil prices and a transition to a servicebased economy drive a reduction in oil use. This reduction causes NMVOC emissions to decline, independent of climate or air pollution control policies. Assuming neither climate nor further air quality policies beyond 2005 (BL FRZ), the emissions increase from $150 \mathrm{Tg}$ NMVOC/yr in 2005 to around $220 \mathrm{Tg}$ NMVOC/yr by 2060, 


\section{Emission maps $\mathrm{SO}_{2}$ and NOX}

NOX 2005 BL FRZ

NOX 2050 BL FRZ
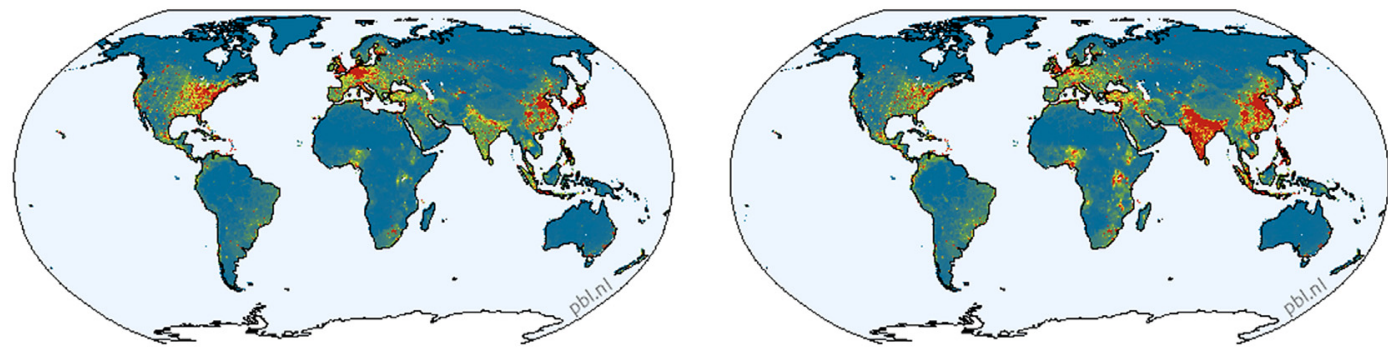

NOX 2050 BL CLE KZN

NOX 2050450 CLE KZN
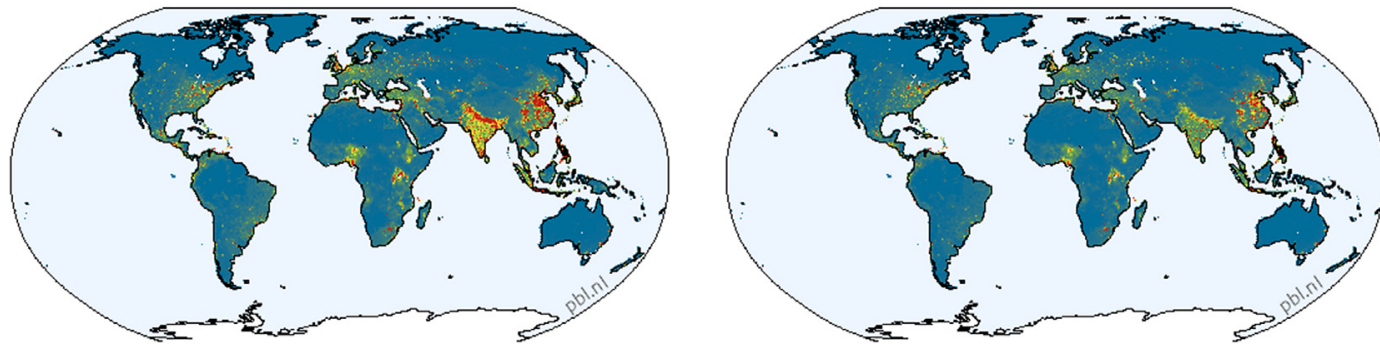

$\mathrm{SO} 22005 \mathrm{BL} F \mathrm{RZ}$

$\mathrm{SO} 22050 \mathrm{BL} F R Z$
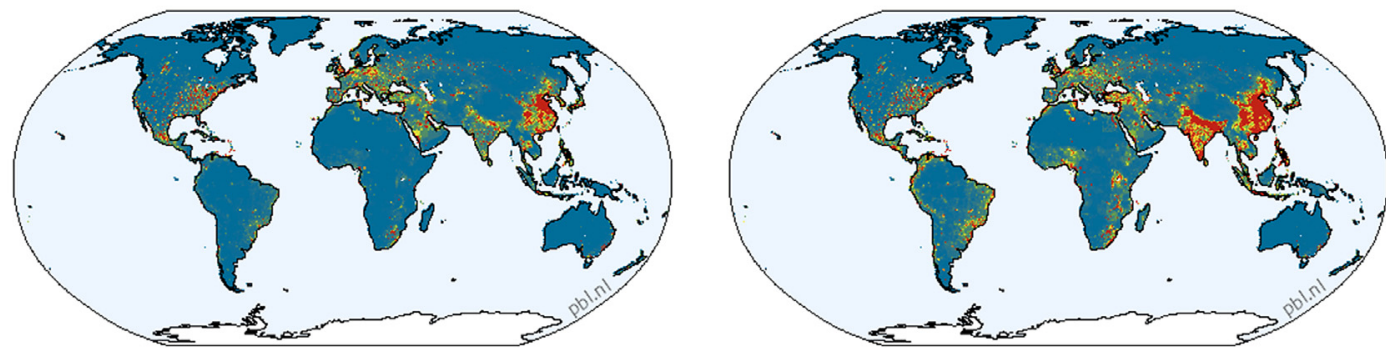

SO2 $2050 \mathrm{BL} C L E$ KZN

SO2 2050450 CLE KZN
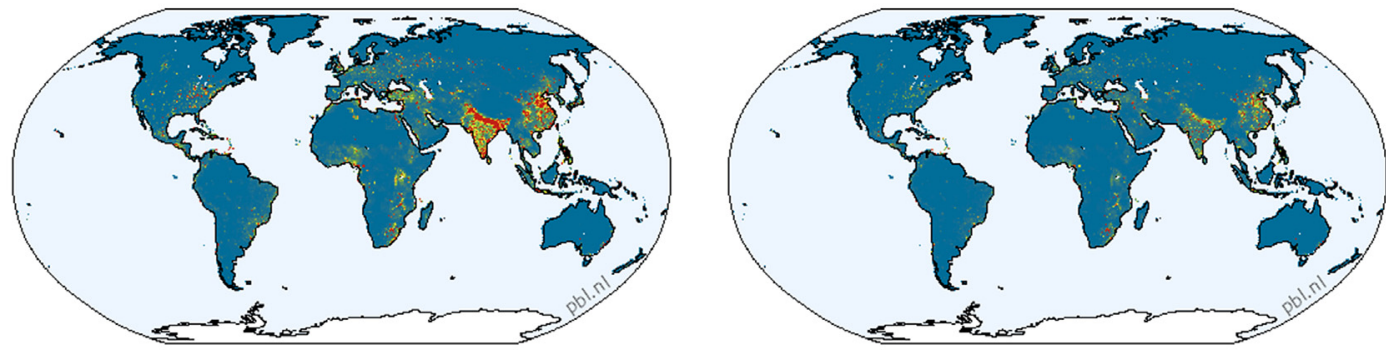

Legend

emissions ( $\left.k g m^{\wedge}-2 s^{\wedge}-1\right)$

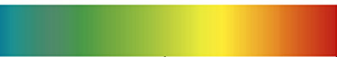

Low: 0

High : 1 - 010

Fig. 4. Spatially resolved $\left(0.5 \times 0.5^{\circ}\right)$ emissions for $\mathrm{SO}_{2}$ and $\mathrm{NO}_{\mathrm{X}}$ downscaled from region to country and grid level maps (with emissions of $\mathrm{NO}_{\mathrm{X}}$ and $\mathrm{SO}_{2}$ in $\mathrm{kg} \mathrm{m}^{-2} \mathrm{~s}^{-1}$ ).

while with climate policies (450 FRZ) the NMVOC emissions moreor-less stabilize at the current level. Obviously, relatively the largest impact of climate policies is expected for cases with little additional air quality legislation, owing to a decrease of losses and the large contribution of transport emissions which can be effectively reduced by bringing down reliance on oil. Additionally, air pollution policies can reduce emissions further through end-of-pipe technologies. The analyzed scenarios suggest that the most stringent combination of climate and air quality policies could reduce emissions of NMVOC by nearly $75 \%$ by the end of the century. 

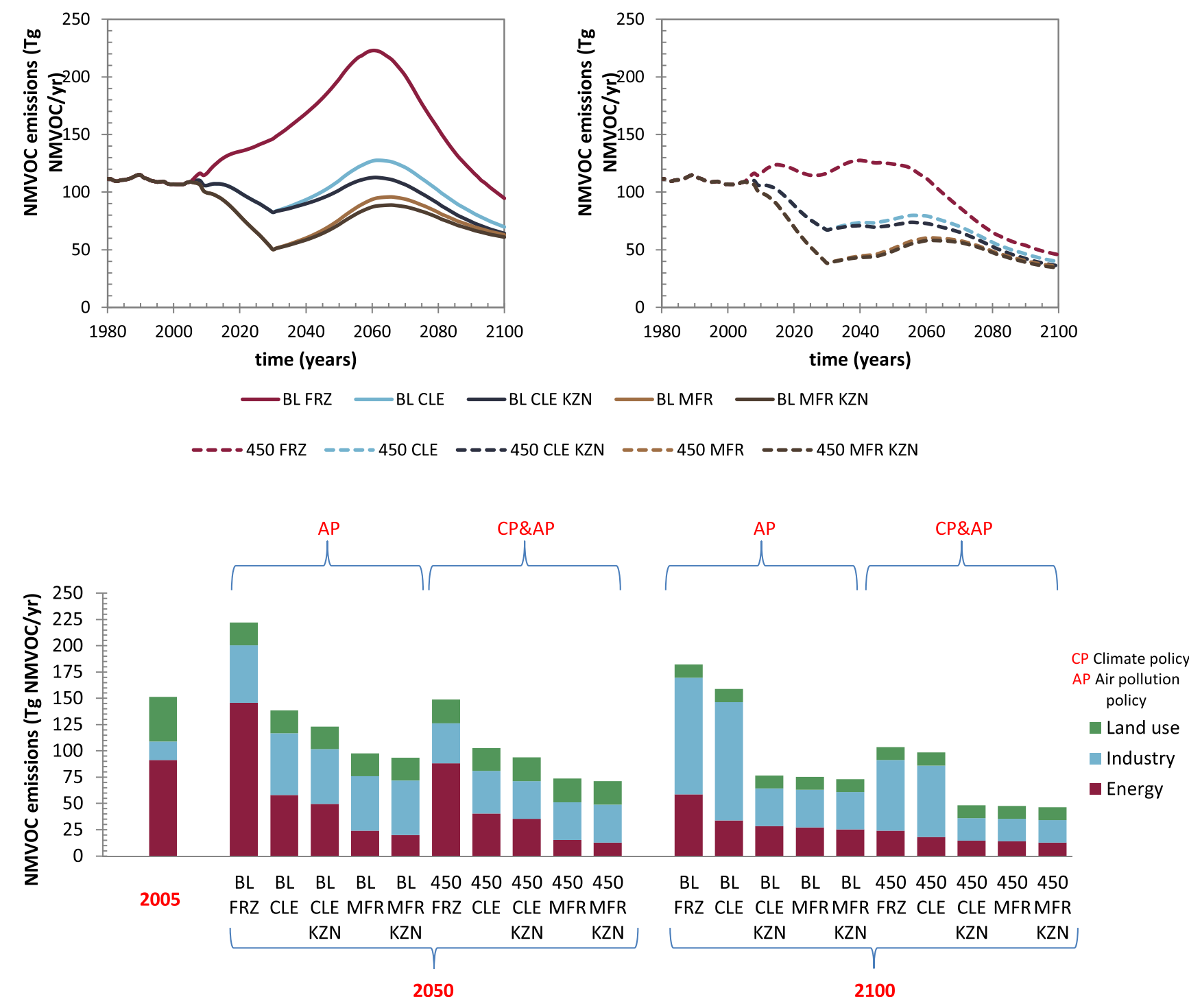

BL BL BL BL BL 450450450450450 FRZ CLE CLE MFRMFR FRZ CLE CLE MFRMFR

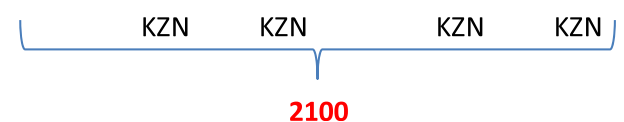

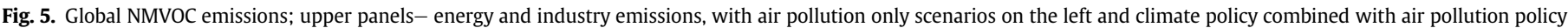

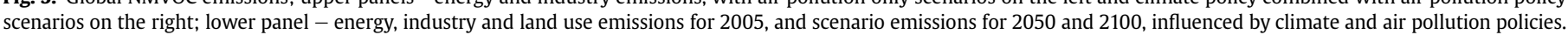

\subsection{CO emissions}

In general, about half of anthropogenic $\mathrm{CO}$ emissions originates from incomplete combustion in the residential and commercial sectors and one-third from road transport. As for NMVOC emissions, the reduced use of oil after 2060, cause the CO emissions to decline independent from climate policy or air pollution control policies. In general, air pollution policies have a relatively strong impact on $\mathrm{CO}$ emissions (Fig. 6).

In the CLE scenarios, the decrease of EFs will result in a continued decline of global emissions, leading to $25 \%$ reduction by 2030 compared to 2005. This decoupling between economic growth and $\mathrm{CO}$ emissions is related to the declining use of coal and fuel wood and to further reductions of emissions from vehicles. The introduction of alternative propulsion systems for vehicles could also lower the CO emissions further (Dorado et al., 2003; Chang and McCarty, 1996). The introduction of climate policy has a similar impact as for $\mathrm{NO}_{\mathrm{X}}$ and $\mathrm{SO}_{2}$. However, at the end of the century a larger share of emissions remain, partly because a larger share of emissions originates from land use change. Although these emissions only represent a small share of the total at the moment, reduction of $\mathrm{CO}$ emissions from the energy system and industry implies a much larger share for land-use change emissions at the end of the century.

\subsection{Carbonaceous particles $-B C$ and $O C$ emissions}

Uncertainties surrounding black carbon (BC) and organic carbon (OC) emissions are large (Bond et al., 2013; Granier et al., 2011; Lamarque et al., 2010; Dentener et al., 2006; Bond et al., 2004). Contrary to $\mathrm{SO}_{2}$ or $\mathrm{NO}_{\mathrm{x}}$, a significant share of the emissions originates from open biomass burning, especially for OC. For anthropogenic sources from the energy system, emissions from combustion of solid fuels (biomass and coal) for cooking and heating and diesel fuel in the transport sector are among the largest contributors worldwide. In our scenarios, BC and OC emissions are strongly influenced by 1) policies and trends in fuel use in the residential sector, 2 ) reduction of deforestation rates and 3 ) 

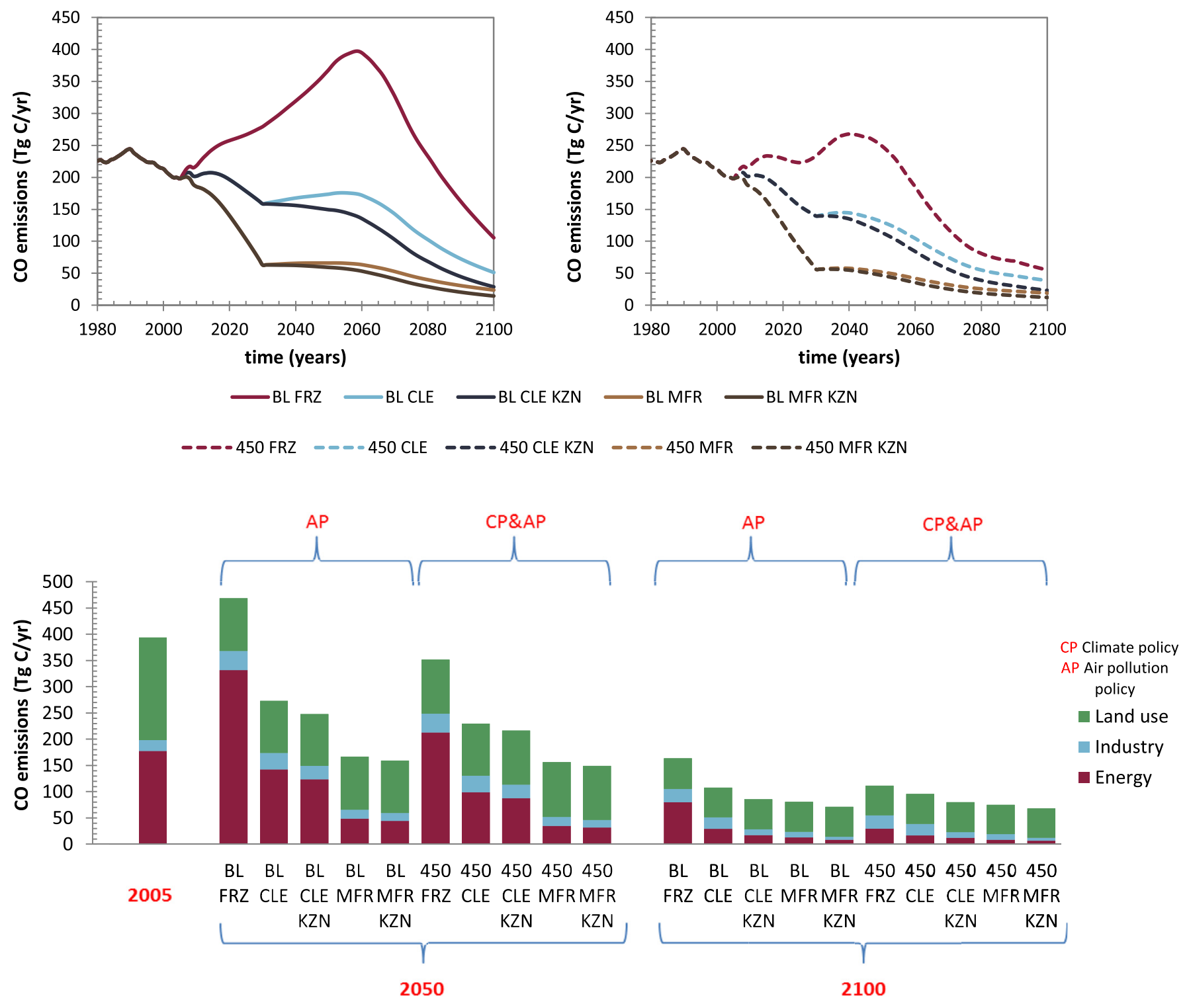

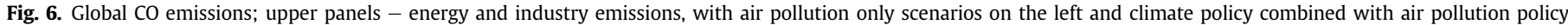

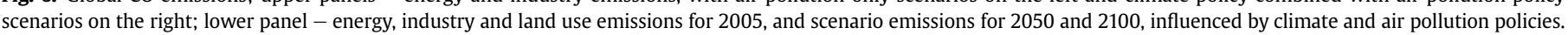

introduction of air pollution policies in transport sector (see Fig. 7). Furthermore, especially in developing regions, dedicated policies to introduce a fuel switch from traditional biomass to cleaner energy sources or further electrification can significantly increase early reductions in the residential sector.

For BC, if no further air quality measures are taken (BL FRZ scenario) BC emissions are projected to be 30\% higher in 2030 than in 2005. The important reductions brought by air pollution scenarios (CLE and MFR) are achieved in the residential sector by improved efficiency of appliances (stoves) and policies in the transport sector (diesel particulate controls). Some additional reductions are also achieved as a result of a fuel switch, i.e. move from traditional biomass and coal to modern clean energy sources for cooking and heating.

In our scenarios OC follows more or less the same temporal development as $\mathrm{BC}$, although it should be noted that even if current legislation is implemented, emissions remain relatively high towards the middle of the century (see Fig. 8). Implementation of stringent air pollution control and climate policy (450 MFR KZN) could reduce $\mathrm{BC}$ and $\mathrm{OC}$ emissions related to combustion of fuels substantially.

\section{Co-benefits of climate policy on air pollution control: impact on air pollutant emissions}

Implementation of a combined set of climate and air pollution policies affects air pollutant levels in different ways; the co-benefits and resulting air emission trends from 2005 to 2100 are discussed here. Fig. 9 summarizes the results for $\mathrm{NO}_{\mathrm{X}}, \mathrm{SO}_{2}, \mathrm{CO}$ and $\mathrm{NMVOC}$ by plotting the emissions as a function of time (panel $a-c$ ) and as a fraction of the BL-FRZ scenario versus the reduction of $\mathrm{CO}_{2}$ emissions (panel $d$ ). For 2050, the co-benefits of climate policy are presented in Fig. 9d, where future air pollution policy would move emissions along the y-axis only, while climate policy would move emissions jointly across the $\mathrm{x}$-axis and $\mathrm{y}$-axis, depending on the level of coupling between climate and air pollution policies.

Reduction values near the diagonal line imply that they are reduced almost at the same rate as $\mathrm{CO}_{2}$ indicating a strong 

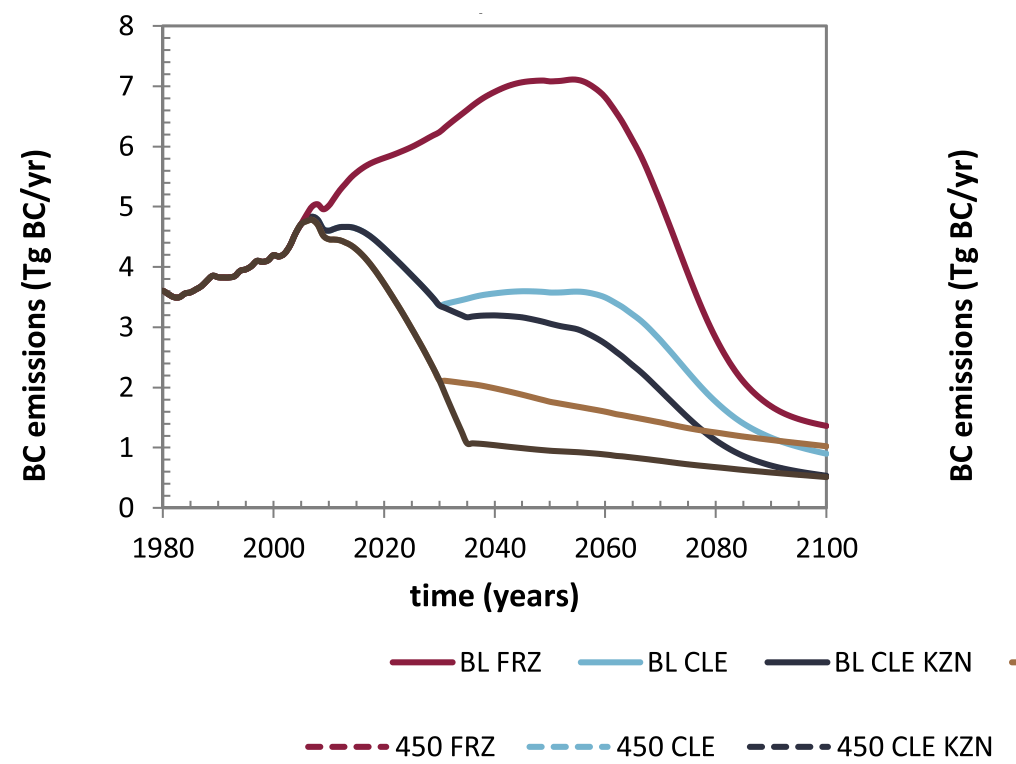

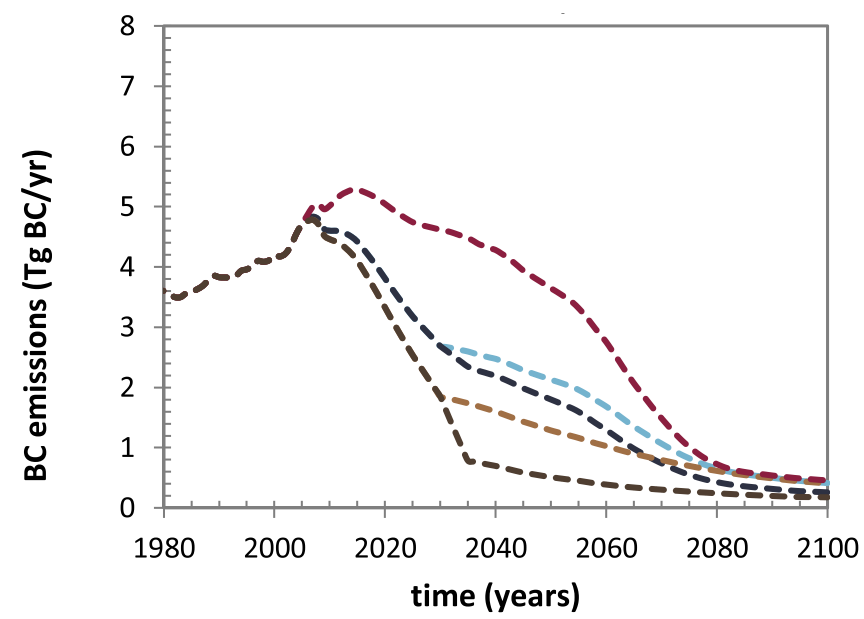

BL MFR $\longrightarrow$ BL MFR KZN

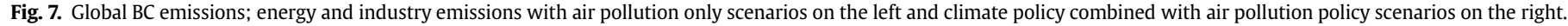
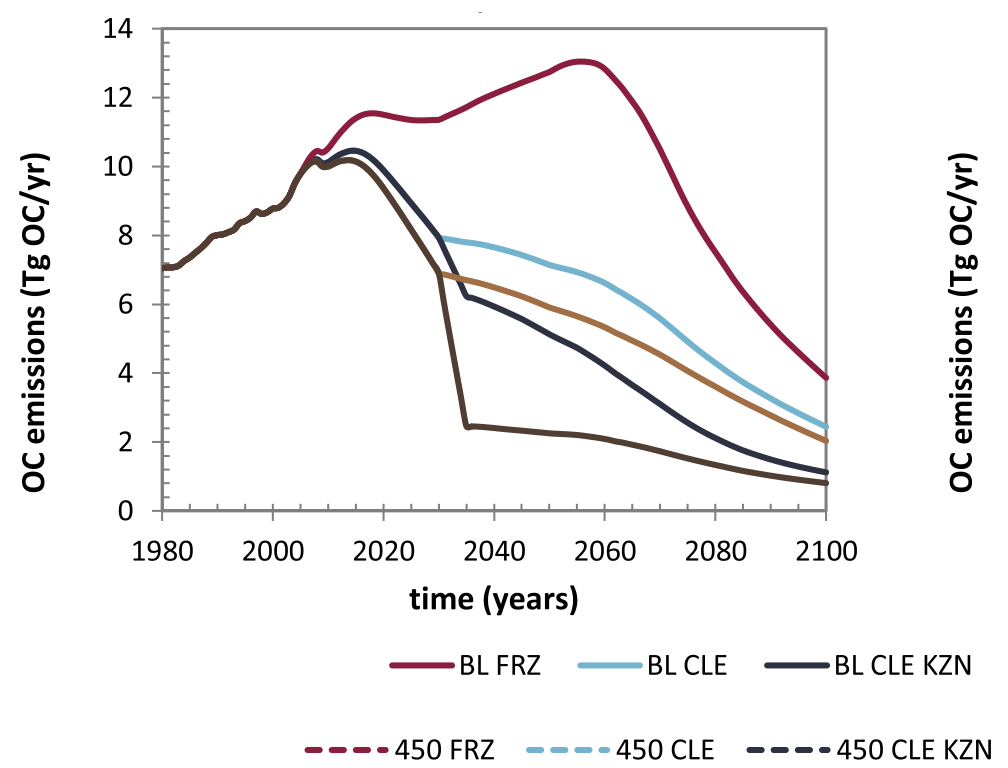

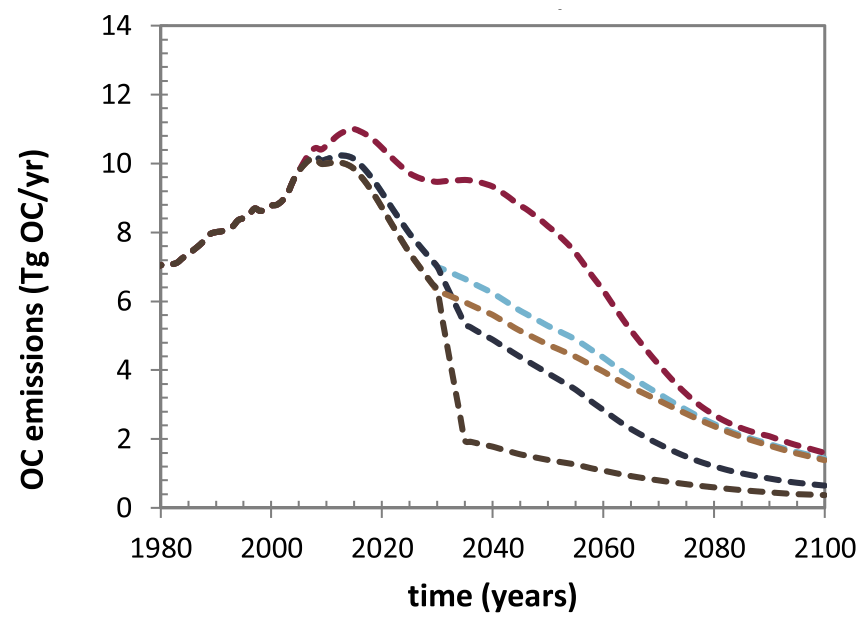

BL MFR BL MFR KZN

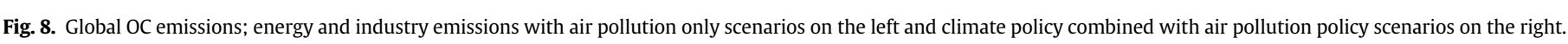

coupling. The figure clearly shows that future air pollution policies can benefit from climate policies in reducing air pollutant emissions. $\mathrm{SO}_{2}$ reductions profit the most from climate policy (see Fig. 9), reducing nearly two thirds of 2005 emission levels without air pollution control measures ( $450 \mathrm{FRZ}$ ). $\mathrm{SO}_{2}$ emissions could drop to levels close to zero by 2100 by a combination of climate policies with strict air pollution policies (450 CLE KZN and stricter scenarios). Roughly, a $10 \%$ reduction in $\mathrm{CO}_{2}$ emissions leads to a simultaneous reduction of $\mathrm{SO}_{2}$ emissions by $10 \%$.

$\mathrm{NO}_{\mathrm{X}}$ emission reduction also benefits from climate policy, but to a lesser extent: here, emissions levels in 2100 could decrease by $40 \%$ due to climate policy alone ( $450 \mathrm{FRZ}$ ) compared to 2005 , while an even larger decrease in emissions is realized with respect to a business as usual scenario (BL FRZ) of over $45 \%$ by 2050 . In contrast, an incremental improvement of current air pollution policies (BL CLE KZN) leads to an emission decline by more than $50 \%$ compared to 2005 levels. Similar to $\mathrm{SO}_{2}$, a combination of climate mitigation and strict air pollution policies (e.g. 450 CLE KZN) would reduce emissions more substantially (see also Fig. 2).

Solvent use is an important source of NMVOC emissions and becomes the dominating source by 2100 . Introducing climate policy has only a modest effect on mid-century emissions, but a stronger impact by the end of the century. The high level of emissions can be attributed to an increase in the chemical industry, and use of paint and personal products, especially in the developing world. Air pollution policies beyond current legislation are projected to be essential in reaching low NMVOC emission levels, by reducing industrial sources.

The significant decrease in oil use in the second half of the century has important implications for emissions of NMVOC, CO, but also BC and OC, leading to their decline. Such a development in the baseline leads to a smaller effect in mitigation potential for 

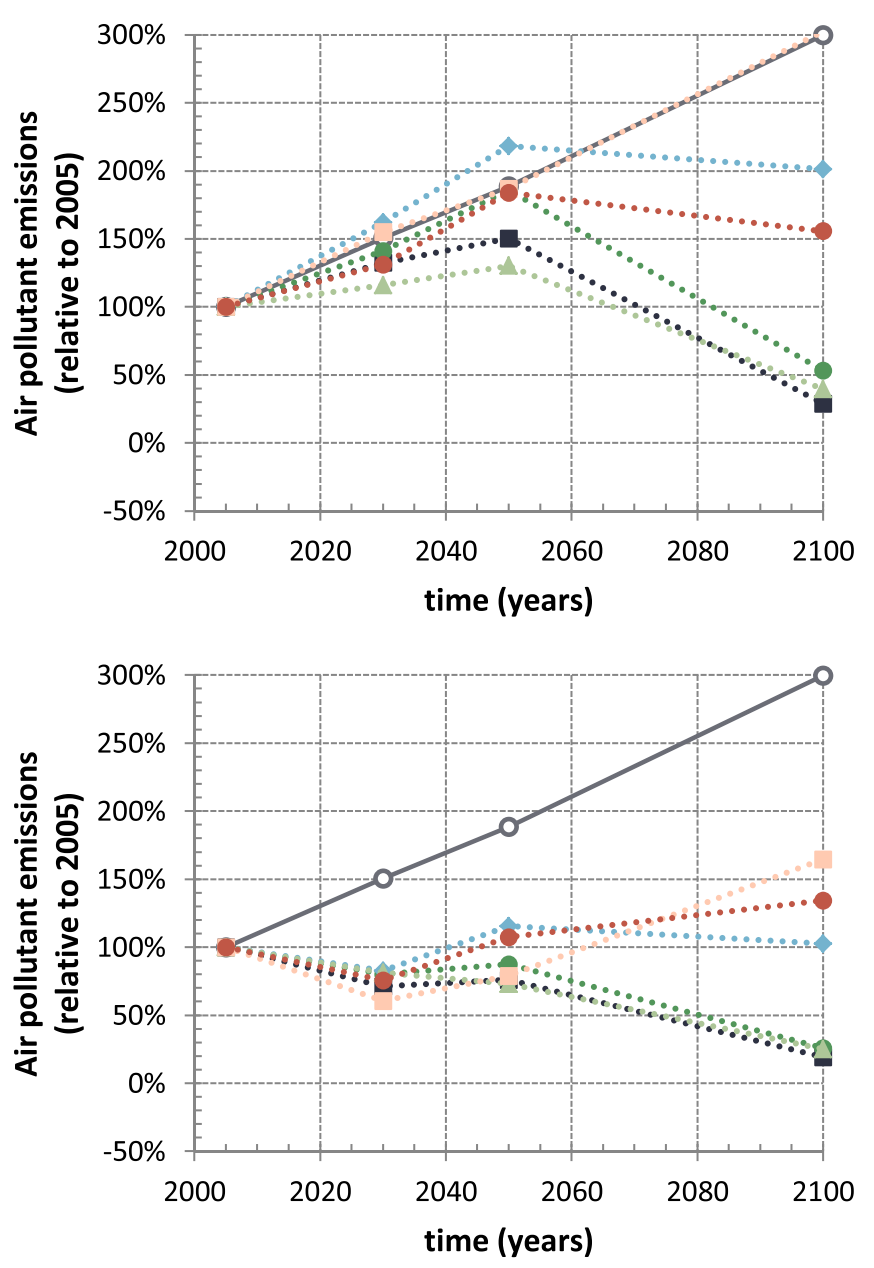

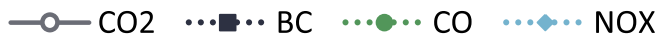
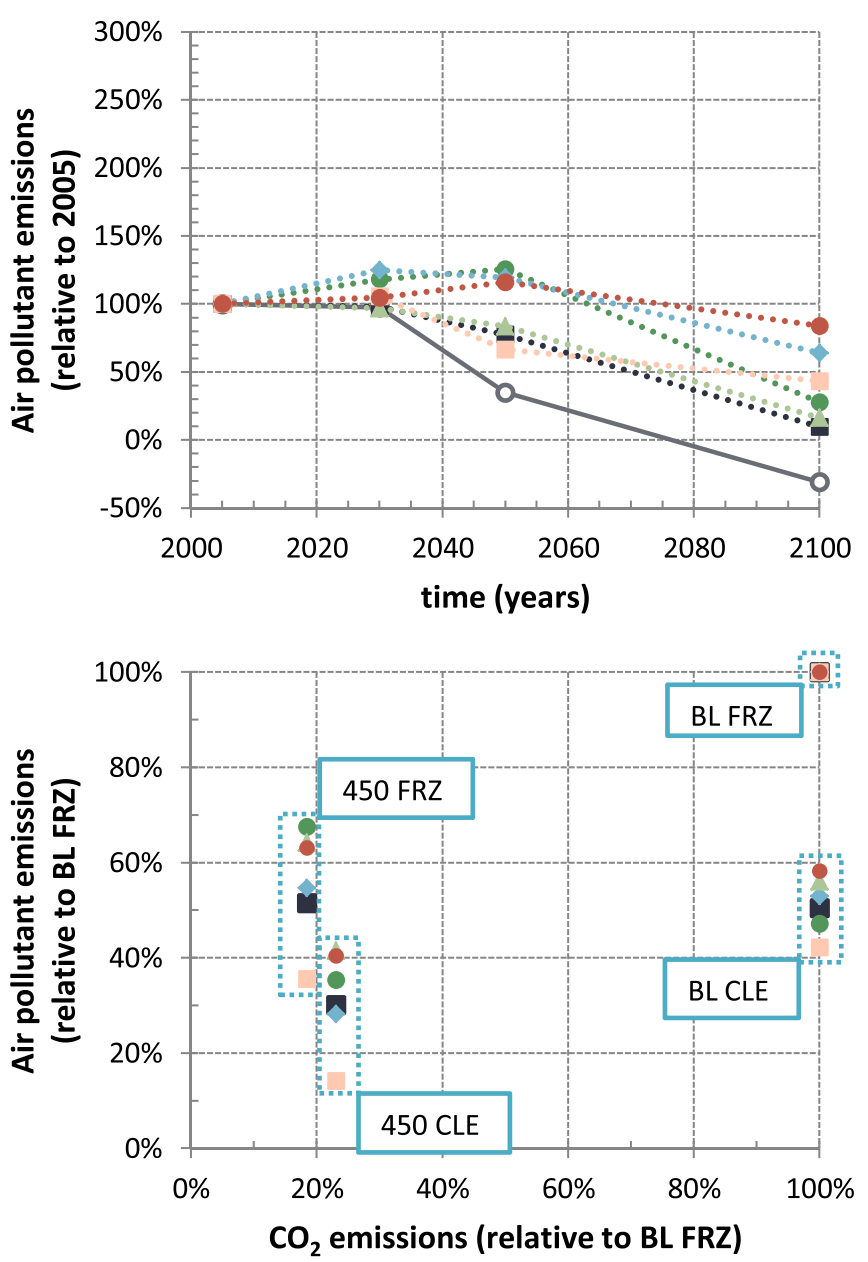

$\ldots$ OC $\cdots$ OC $\quad \ldots$ SO 2 NMVOC

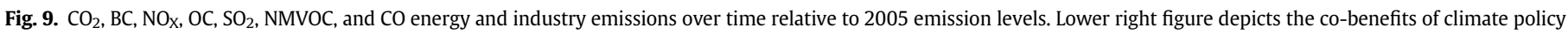
by comparing relative $\mathrm{CO}_{2}$ emission levels to air pollutant emissions in 2050 .

climate policies and stricter air pollution policies. Also, an important switch away from solid fuels for cooking and heating, reducing $\mathrm{BC}$ and $\mathrm{OC}$ emissions.

The scenarios that strengthen the air pollution policies after 2030 (CLE KZN and MFR KZN) show the largest effects toward the end of the century, as the EFs have then declined the most with respect to those in an MFR scenario. Strengthened air pollution policies can bridge the gap between emission reductions of the very strict (MFR) air pollution scenarios and those implementing current legislation. Combined with climate policies, the resulting reduction can become more or less equal (for $\mathrm{NO}_{\mathrm{X}}$ and $\mathrm{CO}$ ) or surpass $\left(\mathrm{SO}_{2}\right.$ and NMVOC) those under very strict air pollution policies.

\section{EDGAR and GAINS comparison}

In this study, the historic 2005 emission factors originate from the EDGAR v4.2 database while the activity levels are based on the IMAGE model. For the period up to 2030, emission factors are based on the GAINS scenarios. Therefore, here we compare the absolute emission levels of IMAGE to these original sources, i.e. for the historical period with the EDGAR v4.2 emission inventory, and for the future period with the GAINS projections for the ECLIPSE V4a scenario (Klimont et al., in preparation, 2016), see Fig. 10.

In principle the comparison shows similar emissions in TIMER and EDGAR v4.2, with differences of 5\%-20\%. One cause of these differences is that in IMAGE, activities are already simulated in the 1970-2005 period, leading to some differences with reported activity data (see e.g. van Ruijven et al., 2009). Differences are relatively small on the level of total primary energy consumption, but are typically of the same order of magnitude (5-20\%) at the sector/ energy carrier level. The differences between EDGAR v4.2 and GAINS are of a similar order. The comparison of the IMAGE and GAINS scenarios shows that for several components both scenario sets lead to comparable results. However for BC and CO emissions, about $10 \%$ of the emissions could not be attributed to an IMAGE emission source category. For OC this factor is about $17 \%$ of total emissions. These unattributed emissions are included in the GAINS emission levels in Fig. 10. Furthermore, the differences between EDGAR and GAINS are a result of different emission factors used, but also because of large uncertainties in estimates of activities and emissions from solvent use, biomass use and cooking. GAINS also includes a number of sources that are not part of EDGAR v4.2, specifically high-emitting vehicles, residential trash burning and kerosene wick lamps. These are especially important, to varying extent, for $\mathrm{NO}_{\mathrm{X}}, \mathrm{CO}, \mathrm{BC}$, and $\mathrm{OC}$, explaining at least partly higher GAINS estimates (Klimont et al., in preparation, 2016). Moreover, variations in the underlying economic data play a major role in explaining the differences including uncertainties in economic 

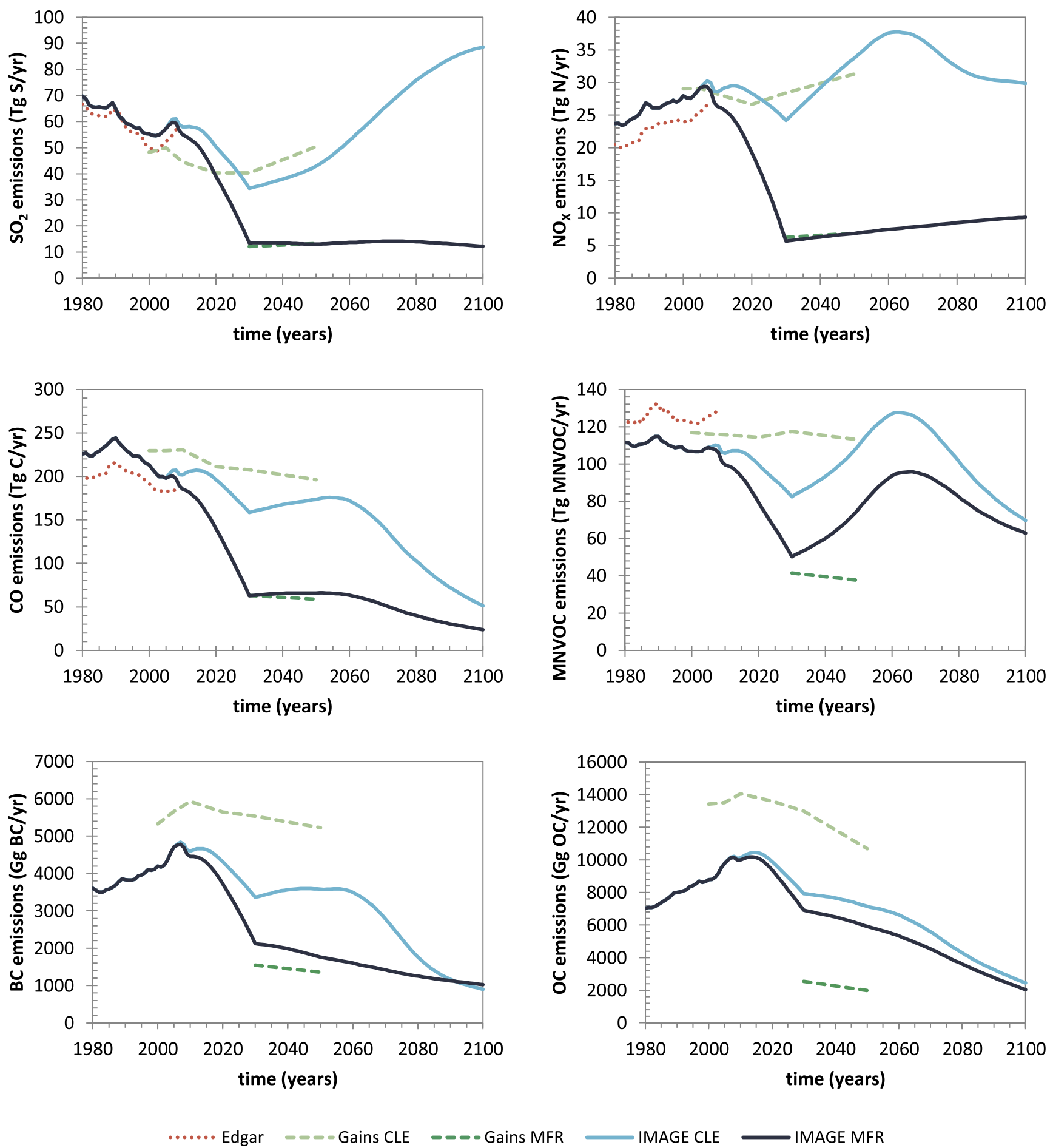

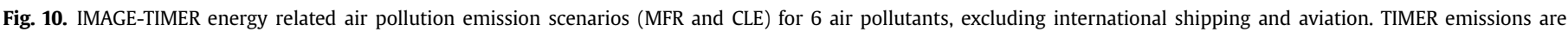
compared with historical (1970-2005) EDGAR v4.2, 2000-2050 GAINS ECLIPSEv4a CLE and 2030-2050 GAINS ECLIPSEv4a MFR emissions.

activity levels, fuel choice and characteristics of the technology considered.

\section{Discussion and conclusions}

The scenarios presented in this article explore a wide range of future air pollution trajectories, with a regional to global long-term perspective. The scenarios systematically explore two key uncertainties: the stringency of climate policy and the stringency of air pollution control. The resulting range of emission trajectories is much wider than the original RCPs. This range including the description of underlying assumptions - makes the scenario set attractive for exploring the impacts of air pollution control, in conjunction with climate policy. The purpose of developing this wide set of scenarios was to respond to three limitations of currently available scenarios: limited exploration of the full range of possible air pollution futures (as in the RCPs), the rather short-term, from the perspective of climate discussion, and often 
only regional or sectoral focus of air pollution projections. The newly developed scenarios have made progress in these areas.

The developed scenarios have some limitations, specifically with respect to potential impact of air pollution policies on land use, including agricultural waste burning. In some regions open burning of biomass contributes strongly to local pollution episodes and would be targeted by air pollution policy; such scenarios were not explored here. These limitations could be addressed in future work. Furthermore, for specific regions, more detailed scenarios exist that provide finer spatial resolution and a much more specific representation of policies.

The implementation of climate mitigation policies is highly relevant for air pollution control, due to important co-benefits between climate policy and reduction of air pollutant emissions. Especially for some species $\left(\mathrm{SO}_{2}\right.$ and $\left.\mathrm{NO}_{\mathrm{X}}\right)$, climate policy may result in substantial co-benefits. This is for instance illustrated by the fact that implementing stringent climate policies can reduce emissions of these species further than even the most tight air pollution policies in place. The combination of air pollution and climate policy could form an effective strategy for reducing emissions, especially in Asian regions now characterized by very high emission levels.

After 2030, additional policies that go beyond current policies are necessary to avoid an increase in air pollutant emissions. The implementation of a CLE scenario is expected to halt the growth and stabilize global emissions towards 2030 for most of the species $\left(\mathrm{NO}_{\mathrm{X}}, \mathrm{BC}, \mathrm{OC}, \mathrm{CO}, \mathrm{NMVOC}\right)$ and generate substantial decreases for $\mathrm{SO}_{2}$. At the regional level, developments are more diverse. The maximum feasible reduction scenario would result in a more than $75 \%$ reduction in 2030 compared to the 2005 emissions of $\mathrm{NO}_{\mathrm{X}}, \mathrm{SO}_{2}$ and $\mathrm{CO}$. However, unless stricter controls after 2030 are enforced, emissions might start to increase again, primarily for $\mathrm{SO}_{2}$ and $\mathrm{NO}_{\mathrm{X}}$, due to increases in activity levels induced by population and GDP growth. Alternatively, introduction of ambitious climate policies could help in reversing these trends.

In the period after 2030 , the simulations are based on the assumed relationship between economic growth and emissions factors. There is substantial evidence that wealthier societies tend to introduce more stringent air pollution control policies, at least for some pollutants (e.g. trends are observed for $\mathrm{SO}_{2}$, but not for $\mathrm{CO}_{2}$ ). There is substantial debate on the question whether income can be seen as a real driver of this process (or instead policy interventions) and whether the observations for some income levels and species can be applied more universally. Here, we have used income to derive possible trajectories for future emission factors. However, it is not implied that such emission factor improvements will be implemented automatically; rather they need a welldesigned and targeted multi-pollutant policy.

In the context of climate policy, stringent air pollution control policies are most relevant by mid-century. Towards the end of the century air pollutant emissions strongly decrease given the shift towards renewable energy and significant improvements in energy efficiency. Mid-century maximum feasible reduction policies can have a considerable impact. To reach ambitious air pollution control targets during the century, strict air pollution control policies are required also in a world with effective greenhouse gas mitigation policies in place. The most promising perspective to reach low air pollutant levels would be combining important reductions of $\mathrm{CO}_{2}$ and other long-lived greenhouse gases, with accelerated action on air pollutants.

\section{Acknowledgements}

This paper is written as a follow-up of the EU FP7 Project PEGASOS (Pan-European Gas-Aerosols-Climate Interaction Study -
Atmospheric Chemistry and Climate Change Interactions, grant agreement no: 265148). The results presented in this study are from the reports of the PEGASOS project, which was led by PBL (PBL Netherlands Environmental Impact Assessment Agency) and benefitted from the contribution of two institutes involved in the project: IIASA (International Institute for Applied Systems Analysis) and JRC (Joint Research Centre), collaborating thus with the GAINS and respectively EDGAR research teams. The GAINS team provided emission factors for six air pollutants included in the CLE (activity and emissions data implying the implementation of existing current legislation) and MFR (emissions and activity data implying besides the current legislation also the use of most of the todays best available technologies) data sets for 2030 and the EDGAR group provided the sectoral Implied Emission Factors from 1970 to 2008 for the 26 IMAGE regions that were used for model calibration. Data availability via ECCAD (http://eccad.sedoo.fr) platform under the scenario family PBL-PEGASOSv2.

\section{Appendix A. Supplementary data}

Supplementary data related to this article can be found at http:// dx.doi.org/10.1016/j.atmosenv.2016.05.021

\section{References}

Amann, M., Bertok, I., Borken-Kleefeld, J., Cofala, J., Heyes, C., Höglund-Isaksson, L. Klimont, Z., Nguyen, B., Posch, M., Rafaj, P., Sandler, R., Schöpp, W., Wagner, F., Winiwarter, W., 2011. Cost-effective control of air quality and greenhouse gases in Europe: modeling and policy applications. Environ. Model. Softw. 26, 1489-1501.

Amann, M., Bertok, I., Cofala, J., Gyarfas, F., Heyes, C., Klimont, Z., Schöpp, W. Winiwarter, W., 2005. Baseline Scenarios for the Clean Air for Europe (CAFE) Programme. Final Report, p. 79.

Amann, M., Klimont, Z., Wagner, F., 2013. Regional and global emissions of air pollutants: recent trends and future scenarios. Annu. Rev. Environ. Resour. 38, 31-55.

Bollen, J., Brink, C., 2012. Air Pollution Policy in Europe: Quantifying the Interaction with Greenhouse Gases and Climate Change Policies. CPB Discussion Paper. CPB Netherlands Bureau for Economic Policy Analysis.

Bond, T.C., Doherty, S.J., Fahey, D.W., Forster, P.M., Berntsen, T., Deangelo, B.J. Flanner, M.G., Ghan, S., Kärcher, B., Koch, D., Kinne, S., Kondo, Y., Quinn, P.K. Sarofim, M.C., Schultz, M.G., Schulz, M., Venkataraman, C., Zhang, H., Zhang, S., Bellouin, N., Guttikunda, S.K., Hopke, P.K., Jacobson, M.Z., Kaiser, J.W. Klimont, Z., Lohmann, U., Schwarz, J.P., Shindell, D., Storelvmo, T., Warren, S.G. Zender, C.S., 2013. Bounding the role of black carbon in the climate system: a scientific assessment. J. Geophys. Res. Atmos. 118, 5380-5552.

Bond, T.C., Streets, D.G., Yarber, K.F., Nelson, S.M., Woo, J.H., Klimont, Z., 2004 A technology-based global inventory of black and organic carbon emissions from combustion. J. Geophys. Res. D Atmos. 109.

Bouwman, L., Kram, T. Klein-Goldewijk, K., 2006. Integrated Modelling of Global Environmental Change. An Overview of IMAGE 2.4. Netherlands Environmental Assessment Agency, Bilthoven.

Chang, Y.-F., Mccarty, J.G., 1996. Novel oxygen storage components for advanced catalysts for emission control in natural gas fueled vehicles. Catal. Today 30 $163-170$.

Chuwah, C., Van Noije, T., Van Vuuren, D.P., Hazeleger, W., Strunk, A., Deetman, S., Beltran, A.M., Van Vliet, J., 2013. Implications of alternative assumptions regarding future air pollution control in scenarios similar to the Representative Concentration Pathways. Atmos. Environ. 79, 787-801.

Cofala, J., Amann, M., Klimont, Z., Kupiainen, K., Höglund-Isaksson, L., 2007. Scenarios of global anthropogenic emissions of air pollutants and methane until 2030. Atmos. Environ. 41, 8486-8499.

Dentener, F., Kinne, S., Bond, T., Boucher, O., Cofala, J., Generoso, S., Ginoux, P. Gong, S., Hoelzemann, J.J., Ito, A., Marelli, L., Penner, J.E., Putaud, J.P., Textor, C. Schulz, M., Van Der Werf, G.R., Wilson, J., 2006. Emissions of primary aeroso and precursor gases in the years 2000 and 1750 prescribed data-sets for AeroCom. Atmos. Chem. Phys. 6, 4321-4344.

Dorado, M.P., Ballesteros, E., Arnal, J.M., Gomez, J., Lopez, F.J., 2003. Exhaust emissions from a diesel engine fuelled with transesterified waste olive oil. Fuel 82 $1311-1315$.

EC-JRC/PBL, 2011. Emission Database for Global Atmospheric Research (EDGAR) release version 4.2

Granier, C., Bessagnet, B., Bond, T., D’angiola, A., van der Gon, H.D., Frost, G.J., Heil, A. Kaiser, J.W., Kinne, S., Klimont, Z., Kloster, S., Lamarque, J.F., Liousse, C., Masui, T. Meleux, F., Mieville, A., Ohara, T., Raut, J.C., Riahi, K., Schultz, M.G., Smith, S.J. Thompson, A., Van Aardenne, J., Van Der Werf, G.R., Van Vuuren, D.P., 2011 Evolution of anthropogenic and biomass burning emissions of air pollutants at 
global and regional scales during the 1980-2010 period. Clim. Change 109, 163-190.

IPCC, 2006. 2006 IPCC Guidelines for National Greenhouse Gas Inventories.

Jacob, D.J., Winner, D.A., 2009. Effect of climate change on air quality. Atmos. Environ. 43, 51-63.

Klimont, Z., Cofala, J., Xing, J., Wei, W., Zhang, C., Wang, S., Kejun, J., Bhandari, P., Mathur, R., Purohit, P., Rafaj, P., Amann, M., Chambers, A., Hao, J., 2009. Projections of SO2, NOx and carbonaceous aerosols emissions in Asia. Tellus, Ser. B Chem. Phys. Meteorology 61, 602-617.

Klimont, Z., Hoeglund-Isaksson, L., Heyes, C., Rafaj, P., Schoepp, W., Cofala, J., Purohit, P., Borken-Kleefeld, J., Kupiainen, K., Kiesewetter, G., Winiwarter, W., Amann, M., Zhao, B., Wang, S.X., Bertok, I., Sander, R., 2016. Global Scenarios of Air Pollutants and Methane: 1990-2050 in preparation.

Lamarque, J.F., Bond, T.C., Eyring, V., Granier, C., Heil, A., Klimont, Z., Lee, D., Liousse, C., Mieville, A., Owen, B., Schultz, M.G., Shindell, D., Smith, S.J. Stehfest, E., Van Aardenne, J., Cooper, O.R., kainuma, M., Mahowald, N. Mcconnell, J.R., Naik, V., Riahi, K., Van Vuuren, D.P., 2010. Historical (1850-2000) gridded anthropogenic and biomass burning emissions of reactive gases and aerosols: methodology and application. Atmos. Chem. Phys. 10, 7017-7039.

McCollum, D.L., Krey, V., Riahi, K., 2012. Beyond Rio: sustainable energy scenarios for the 21 st century. Nat. Resour. Forum 36, 215-230.

McCollum, D.L., Krey, V., Riahi, K., Kolp, P., Grubler, A., Makowski, M. Nakicenovic, N., 2013. Climate policies can help resolve energy security and air pollution challenges. Clim. Change 119, 479-494.

Moss, R.H., Edmonds, J.A., Hibbard, K.A., Manning, M.R., Rose, S.K., Van Vuuren, D.P. Carter, T.R., Emori, S., Kainuma, M., Kram, T., Meehl, G.A., Mitchell, J.F.B., Nakicenovic, N., Riahi, K., Smith, S.J., Stouffer, R.J., Thomson, A.M., Weyant, J.P., Wilbanks, T.J., 2010. The next generation of scenarios for climate change research and assessment. Nature 463, 747-756.

OECD, 2012. OECD Environmental Outlook to 2030. Organisation for Economic Cooperation and Development, Paris.

Rafaj, P., Amann, M., Siri, J.G., 2014. Factorization of air pollutant emissions: projections versus observed trends in Europe. Sci. Total Environ. 494, 272-282.

Rafaj, P., Schöpp, W., Russ, P., Heyes, C., Amann, M., 2013. Co-benefits of post-2012 global climate mitigation policies. Mitig. Adapt. Strategies Glob. Change 18, $801-824$.

Rao, S., Keppo, I., Riahi, K., 2006. Importance of technological change and spillovers in long-term climate policy. Energy J. 27, 123-139.

Rao, S., Pachauri, S., Dentener, F., Kinney, P., Klimont, Z., Riahi, K., Schoepp, W., 2013. Better air for better health: forging synergies in policies for energy access, climate change and air pollution. Glob. Environ. Change 23, 1122-1130.

Riahi, K., Dentener, F., Gielen, D., Grubler, A., Jewell, J., Klimont, Z., Krey, V., McCollum, D., Pachauri, S., Rao, S., Van Ruijven, B., Van Vuuren, D.P., Wilson, C., 2012. Chapter 17-Energy Pathways for Sustainable Development. Global Energy Assessment - toward a Sustainable Future. Cambridge University Press, Cambridge, UK and New York, NY (USA and the International Institute for Applied Systems Analysis, Laxenburg, Austria).

Rogelj, J., Rao, S., McCollum, D.L., Pachauri, S., Klimont, Z., Krey, V., Riahi, K., 2014 a. Air-pollution emission ranges consistent with the representative concentration pathways. Nat. Clim. Change 4, 446-450.

Rogelj, J., Schaeffer, M., Meinshausen, M. Shindell, D.T., Hare, W., Klimont, Z Velders, G.J.M., Amann, M., Schellnhuber, H.J., 2014b. Disentangling the effects of $\mathrm{CO} 2$ and short-lived climate forcer mitigation. Proc. Natl. Acad. Sci. U. S. A. 111, 16325-16330.

Sharma, S., Goel, A., Gupta, D., Kumar, A., Mishra, A., Kundu, S., Chatani, S., Klimont, Z., 2015. Emission inventory of non-methane volatile organic compounds from anthropogenic sources in India. Atmos. Environ. 102, 209-219.

Shindell, D., Kuylenstierna, J.C.I., Vignati, E., Van Dingenen, R., Amann, M. Klimont, Z., Anenberg, S.C., Muller, N., Janssens-Maenhout, G., Raes, F. Schwartz, J., Faluvegi, G., Pozzoli, L., Kupiainen, K., Höglund-Isaksson, L.,
Emberson, L., Streets, D., Ramanathan, V., Hicks, K., Oanh, N.T.K., Milly, G., Williams, M., Demkine, V., Fowler, D., 2012. Simultaneously mitigating nearterm climate change and improving human health and food security. Science 335, 183-189.

Smith, S.J., Wigley, T.M.L., 2006. Multi-gas forcing stabilization with minicam. Energy J. 27, 373-391.

Stern, D.I., 2003. The Environmental Kuznets Curve. International Society for Ecological Economics Internet Encyclopedia of Ecological Economics. http:// www.ecoeco.org/pdf/stern.pdf.

Syri, S., Amann, M., Capros, P., Mantzos, L., Cofala, J., Klimont, Z., 2001. Low-CO2 energy pathways and regional air pollution in Europe. Energy Policy 29, 871-884.

Task Force On Hemispheric Transport Of Air Pollution, 2010. Hemispheric Transport of Air Pollution 2010. Switzerland, UN-ECE, Geneva.

Taylor, K.E., Stouffer, R.J., Meehl, G.A., 2012. An Overview of CMIP5 and the experiment design. Bull. Amer. Meteor. Soc. 93, 485-498.

UNDESA, 2011. World Population Prospects: the 2010 Revision. Population Division of the Department of Economic and Social Affairs of the United Nations Secretariat. http://esa.un.org/unpd/wpp/index.htm.

UNEP \& WMO, 2011. In: Ullstein, B. (Ed.), Integrated Assessment of Black Carbon and Tropospheric Ozone - Summary for Decicion Makers. UNEP and WMO.

van Ruijven, B., De Vries, B., Van Vuuren, D.P., Van Der Sluijs, J.P., 2009. A global model for residential energy use: uncertainty in calibration to regional data. Energy 35, 269-282.

van Ruijven, B., Urban, F., Benders, R.M.J., Moll, H.C., Van Der Sluijs, J.P., de Vries, B., Van Vuuren, D.P., 2008. Modeling energy and development: an evaluation of models and concepts. World Dev. 36, 2801-2821.

van Vliet, J., van den Berg, M., Schaeffer, M., van Vuuren, D.P., den Elzen, M., Hof, A.F., Beltran, A.M., Meinshausen, M., 2012. Copenhagen Accord Pledges imply higher costs for staying below $2^{\circ} \mathrm{C}$ warming: a letter. Clim. Change 113, 551-561.

van Vuuren, D.P., Bouwman, L.F., Smith, S.J., Dentener, F., 2011a. Global projections for anthropogenic reactive nitrogen emissions to the atmosphere: an assessment of scenarios in the scientific literature. Curr. Opin. Environ. Sustain. 3, 359-369.

van Vuuren, D.P., Cofala, J., Eerens, H.E., Oostenrijk, R., Heyes, C., Klimont, Z., Den Elzen, M.G.J., Amann, M., 2006. Exploring the ancillary benefits of the Kyoto Protocol for air pollution in Europe. Energy Policy 34, 444-460.

van Vuuren, D.P., Edmonds, J., Kainuma, M., Riahi, K., Thomson, A., Hibbard, K., Hurtt, G.C., Kram, T., Krey, V., Lamarque, J.F., Masui, T., Meinshausen, M., Nakicenovic, N., Smith, S.J., Rose, S.K., 2011b. The representative concentration pathways: an overview. Clim. Change 109, 5-31.

van Vuuren, D.P., Lucas, P.L., Hilderink, H., 2007. Downscaling drivers of global environmental change: enabling use of global SRES scenarios at the national and grid levels. Glob. Environ. Change 17, 114-130.

van Vuuren, D.P., Meinshausen, M., Plattner, G.K., Joos, F., Strassmann, K.M., Smith, S.J., Wigley, T.M.L., Raper, S.C.B., Riahi, K., de La Chesnaye, F., Den Elzen, M.G.J., Fujino, J., Jiang, K., Nakicenovic, N., Paltsev, S., Reilly, J.M., 2008. Temperature increase of 21st century mitigation scenarios. Proc. Natl. Acad. Sci. U. S. A. 105, 15258-15262.

van Vuuren, D.P., Stehfest, E., Den Elzen, M.G.J., Kram, T., Van Vliet, J., Deetman, S., Isaac, M., Goldewijk, K.K., Hof, A., Beltran, A.M., Oostenrijk, R., Van Ruijven, B. 2011c. RCP2.6: exploring the possibility to keep global mean temperature increase below $2^{\circ} \mathrm{C}$. Clim. Change 109, 95-116.

Wang, S.X., Zhao, B., Cai, S.Y., Klimont, Z., Nielsen, C.P., Morikawa, T., Woo, J.H., Kim, Y., Fu, X., Xu, J.Y., Hao, J.M., He, K.B., 2014. Emission trends and mitigation options for air pollutants in East Asia. Atmos. Chem. Phys. 14, 6571-6603.

Wei, W., Wang, S., Chatani, S., Klimont, Z., Cofala, J., Hao, J., 2008. Emission and speciation of non-methane volatile organic compounds from anthropogenic sources in China. Atmos. Environ. 42, 4976-4988. 